\title{
CONF-95/0144--2 \\ 952456
}

\section{The Effect of TDC Temperature and Density on the Liquid-Phase Fuel Penetration in a D.I. Diesel Engine*}

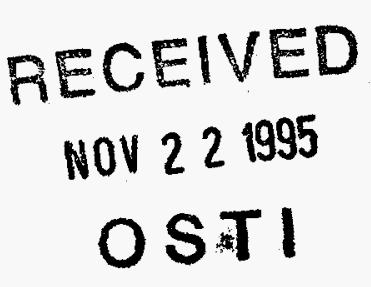

\author{
Christoph Espey** \\ Daimler-Benz AG \\ John E. Dec \\ Sandia National Laboratories
}

\begin{abstract}
A parametric study of the liquid-phase fuel penetration of evaporating Diesel fuel jets has been conducted in a directinjection Diesel engine using laser elastic-scatter imaging. The experiments were conducted in an optically accessible Diesel engine of the "heavy-duty" size class at a representative medium speed $(1200 \mathrm{rpm})$ operating condition. The density and temperature at TDC were varied systematically by adjusting the intake temperature and pressure.

At all operating conditions the measurements show that initially the liquid fuel penetrates almost linearly with increasing crank angle until reaching a maximum length. Then, the liquid-fuel penetration length remains fairly constant although fuel injection continues. At a TDC density of $16.6 \mathrm{~kg} / \mathrm{m}^{3}$ and a temperature of about $1000 \mathrm{~K}$ the maximum penetration length is approximately $23 \mathrm{~mm}$. However, it varies significantly as TDC conditions are changed, with the liquid-length being less at higher temperatures and at higher densities. The corresponding apparent heat release rate plots are presented and the results of the liquid-phase fuel penetration are discussed with respect to the ignition delay and premixed burn fraction.
\end{abstract}

\section{INTRODUCTION}

Optimization of the fuel-air mixing process provides one of the most effective means of adjusting Diesel engine combustion to meet worldwide emission regulations without a loss in engine performance. Accordingly, an improved understanding of the phenomena affecting fuel-air mixing and associated fuel vaporization in the Diesel engine combustion chamber is essential. A considerable effort has been made in recent years to obtain detailed in-cylinder measurements;

\footnotetext{
* This work was performed at the Combustion Research Facility, Sandia National Laboratories and was supported by the Cummins Engine Co. and the U.S. Department of Energy, Defense Programs Technology Transfer Initiative.

* With the Pennsylvania State University at the time this work was conducted.
}

however, additional studies across an extended range of Diesel engine operating conditions are needed to support the development of computer codes by indicating direction for model development and supplying data for model verification.

Optical techniques have been a valuable tool for combustion research because they can provide non-intrusive measurements. In early studies, direct, back-light, and schlieren photography were the standard optical techniques used to investigate the evaporation process [1-10]. Using diffuse back illumination, Kamimoto et al. $[9,10]$ and Browne et al. [5] measured the penetration of the dense liquid portion of the fuel spray in a rapid compression machine and a research engine, respectively. The studies of Kamimoto et al. $[9,10]$ indicated that the majority of the liquid-phase fuel did not penetrate further than $25-30 \mathrm{~mm}$ at the conditions studied, although fuel injection continued and the vapor-phase fuel did progress further into the chamber. Additionally, the study indicated, that this limit is independent of injection pressure. Browne et al. [5] investigated the influence of temperature, fuel properties, and nozzle hole diameter on the penetration of the liquid phase. Based on back-light photography measurements, they reported a maximum liquid-fuel length of 26 to $38 \mathrm{~mm}$ depending on the engine intake conditions and the injector-nozzle hole diameter. They also stated that a decrease in the nozzle diameter led to a shorter liquid length.

Recently there have been a number of advancements in the development of planar laser-based diagnostics that can provide more detailed information than back-light or schlieren photography [11]. To better understand the highly turbulent Diesel spray structure and evaporation process, several studies have been conducted using planar imaging of laser-induced fluorescence [12-21], elastic scattering of the liquid fuel [21-24] and Rayleigh scattering [24,25]. In one of these studies [25], the authors obtained simultaneous quantitative 2-D fuel-vapor concentration measurements and temperature fields as well as liquid fuel measurements. Similar to the back-illumination experiments, all the laser-based studies found that the majority of the liquid-phase does not penetrate beyond a characteristic length while fuel injection and vapor-phase penetration continue. 
For the most part, these earlier planar imaging studies have focused on determining the distribution of liquid- and/or vapor-phase fuel at a single operating condition. Some of the back-illumination photography studies, which are potentially less accurate in distinguishing the liquid and dense-vapor regions of the fuel jet, covered some range of operating parameters. However, for Diesel-like conditions, the literature lacks any studies of the effect of in-cylinder air density on the liquid-phase fuel penetration, or planar-imaging studies of the effect of in-cylinder air temperature on the liquid-phase fuel penetration. Understanding the effect of these parameters on the fuel penetration and vaporization rates is important since Diesel engine designs must account for variations in top dead center (TDC) temperature due to changes in ambient conditions, engine temperatures and amount of intercooling, and variations in TDC density due to altitude and amount of turbocharger boost.

This paper reports liquid-fuel penetration data over a wide range of TDC temperatures and densities. By adjusting the intake temperature and pressure, the liquid-phase distribution was obtained for motored TDC temperatures and densities from 800 to $1100 \mathrm{~K}$ and 11.1 to $33.2 \mathrm{~kg} / \mathrm{m}^{3}$, respectively. These TDC densities correspond to simulated intake air pressures from 0.67 to 2 atmospheres absolute for an engine with a compression ratio of 16:1. The extent of the liquid-phase fuel was measured via planar laser elastic-scatter imaging. Additionally, the effects of the TDC temperature and density on the ignition delay and heat release rate were measured and analyzed.

Following this introduction, the experiment and data acquisition techniques are described. Then, the results are presented and discussed. The liquid fuel penetration and heat release rate are first given in detail for the base condition. Then the effects of the parametric variations of TDC temperature and density on both the liquid-phase fuel distribution and heat release rate are presented and discussed. In the final section, the investigation is summarized and conclusions drawn.

\section{EXPERIMENT DESCRIPTION}

\section{OPTICAL-ACCESS ENGINE}

The optical-access engine used in this study was a single-cylinder, direct-injection, 4-stroke Diesel engine based on a Cummins $\mathrm{N}$-series production engine. The $\mathrm{N}$-series engine is typical of heavy-duty size-class Diesel engines, with a bore of $140 \mathrm{~mm}$ and a stroke of $152 \mathrm{~mm}$. These dimensions are retained in the optical-access engine, and a production Cummins $\mathrm{N}$-series cylinder head is used so that the production engine intake port geometry is also preserved. The incylinder flow field of a similar Cummins $\mathrm{N}$-series research engine has been examined under motored conditions and found to be nearly quiescent [26]. Figure 1 presents a schematic of the engine, and Table 1 summarizes its specifications.

The design of this engine utilizes a classic extended piston with piston-crown window similar to that originally introduced by Bowditch in 1961 [27]. Additional windows located around the top of the cylinder wall provide the orthogo-
TABLE 1. Specifications of the Optical-Access Engine

Engine base type ...........................Cummins N-14, DI Diesel

Number of cylinders ...............................................................1

Cycle .......................................................................... 4-stroke

Number of intake valves......................................................2

Number of exhaust valves.................................................. $1^{\mathrm{a}}$

Combustion chamber...................... Quiescent, direct injection

Bore $139.7 \mathrm{~mm}$ (5.5 in)

Stroke. $152.4 \mathrm{~mm}(6.0 \mathrm{in})$

Combustion chamber diameter. $97.8 \mathrm{~mm}$ (3.85 in)

Displacement. 2.34 liters (142 in $\left.{ }^{3}\right)$

Connecting rod length $304.8 \mathrm{~mm}$ (12.0 in)

Piston pin offset.. None

Compression ratio

a In this optically accessible Diesel engine; one of the two exhaust valves of the production cylinder head was replaced by a window and periscope.

nal optical access required for two-dimensional (2-D) laser imaging diagnostics. These windows allow the laser sheet to enter the cylinder along the axis of the fuel jet (see Fig 1). A window in the cylinder head replaces one of the two exhaust valves to obtain a view of the squish region and the outer portion of the combustion bowl. This additional feature was used in recent studies [24,28-30]; however, it was not used in the experiments presented here. Finally, but perhaps most important for studies of the Diesel fuel jet, this optical access engine incorporates a unique separating cylinder liner to allow rapid cleaning of the windows. A complete description of this engine may be found in Ref. 28.

This research engine is equipped with the Cummins CELECT electronic fuel injector. This closed-nozzle unit injector uses camshaft actuation to build injection pressures. A solenoid valve in the injector body controls the amount of fuel injected and the injection timing upon command from the laboratory computer. For the experiments presented here, the injector was equipped with an 8-hole cup. The hole diameter was $0.194 \mathrm{~mm}$ and the nominal angle of the fuel-jet axis was $14^{\circ}$ downward from horizontal. The injector is instrumented with a Hall-effect needle lift sensor, and injection pressure is determined from strain gage measurements of the force in the pushtube that activates the injector. Table 2 summarizes the specifications of the fuel injector. The injection pressures and needle-lift data presented are typical of those of $\mathrm{N}$-series production engines using this injector at the operating conditions studied.

To minimize vibration, the engine was connected to a balancing box with counter-rotating balancing weights and mounted on a spring-mounted isolation pad. The engine was motored and its speed controlled by a $75 \mathrm{hp}$ dynamometer. An air compressor supplied pressurized intake air that was dehumidified and heated.

Special care was taken to filter the engine intake air and the fuel to remove dirt particles. The intake-air supply compressor was fitted with an intake filter and oil-droplet/air separator. In addition, the air passed through another twostage filter system after it was dehumidified. The first stage contained a $0.01 \mu \mathrm{m}$ filter to remove small particulate matter, 


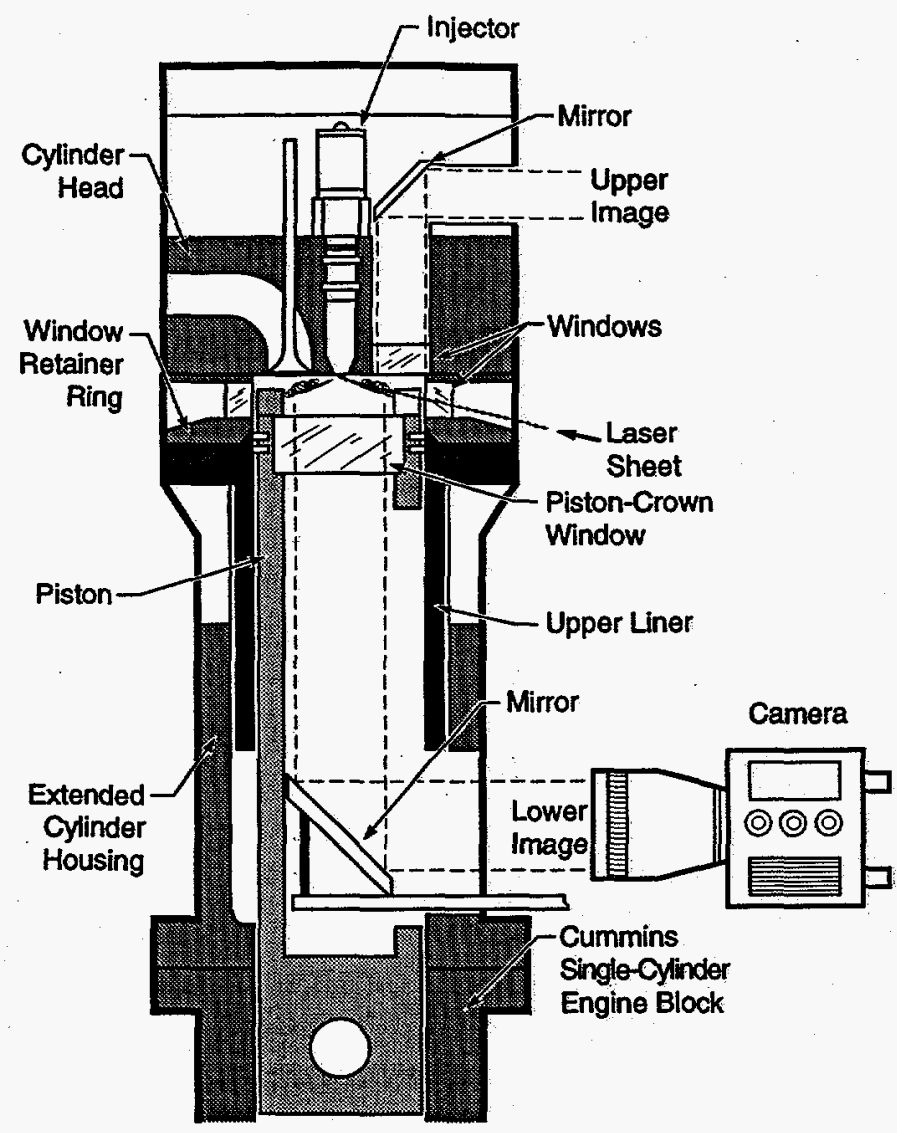

Figure 1. Schematic of optical-access Diesel engine showing the camera location for obtaining the liquid-phase fuel images through the piston-crown window. The upper liner is shown in the operating position.

\section{TABLE 2. Specifications of the Fuel Injector}

Type Cummins CELECT ${ }^{\mathrm{TM}}$

Design Closed-nozzle, unit injector

Number of holes 8, uniformly spaced

Hole diameter $0.194 \mathrm{~mm}$

Length/diameter of holes $(V / d)$ 4.1

Angle of fuel-jet axis (from horizontal) $14^{\circ}$

and the second stage was an activated-charcoal oil-vapor filter to both remove any remaining compressor oil vapor which could condense to form droplets. Fuel was supplied from a $\mathrm{N}_{2}$-pressurized tank to avoid contamination from a pump system. The fuel was continuously filtered with a $0.1 \mu \mathrm{m}$ filter and periodically cleaned to a greater degree by filtering it through a $0.025 \mu \mathrm{m}$ filter.

\section{OPERATING CONDITIONS}

All the data presented in this article were taken at an engine speed of $1200 \mathrm{rpm}$. Before conducting the experiments the engine was heated to $95^{\circ} \mathrm{C}$ by means of electrical heaters on the "cooling" water and lubricating oil circulation systems. To minimize the rate of window fouling and to avoid overheating, the engine was fired once every 20 th engine cycle, at which time the data were acquired. The fuel used for this study was a $\mathbf{4 2 . 5}$ cetane number mixture of the Diesel reference fuels, heptamethylnonane and $\mathrm{n}$-hexadecane. The fuel specifications are summarized in Table 3.

\section{TABLE 3. Reference Fuel}

Composition (vol. \%) $.67 .6 \%$ heptamethylnonane \& $32.4 \%$ n-hexadecane

Specific gravity $0.7865 \mathrm{~g} / \mathrm{cc}$

Cetane number 42.5

Measurements were made at a base operating condition that is representative of Diesel engine conditions, and at various TDC temperatures and densities (covering most of the typical operating range of Diesel engines) above and below those of the base condition. Because the optical-access engine has a compression ratio of only 10:1, intake air temperatures and pressures were increased so that motored TDC conditions were representative of typical Diesel engine conditions. For the base condition, the intake air was heated to $433 \mathrm{~K}$ $\left(160^{\circ} \mathrm{C}\right)$ to obtain a realistic ignition delay and premixed burn fraction. The intake pressure was set to $206 \mathrm{kPa}$ absolute to match the TDC air density of a naturally aspirated engine with the 16:1 compression ratio of a production Cummins $\mathrm{N}$-series engine. This resulted in an estimated TDC temperature and density of $992 \mathrm{~K}$ and $16.6 \mathrm{~kg} / \mathrm{m}^{3}$, respectively, for the motored engine assuming a polytropic coefficient of 1.36. The base operating conditions are given in Table 4

TABLE 4. Base Engine Operating Conditions

Engine speed $1200 \mathrm{rmm}$ Intake air temperature $433 \mathrm{~K}\left(160^{\circ} \mathrm{C}\right)$ Intake air pressure $206 \mathrm{kPa}$ (absolute)

Water temperature $95^{\circ} \mathrm{C}$

Oil temperature $95^{\circ} \mathrm{C}$

Firing rate Every 20th cycle Start of injection $11.5^{\circ}$ BTDC

Fuel injected per cycle $0.0857 \mathrm{ml}$

Average equivalence ratio 0.25

Peak injection pressure $68 \mathrm{MPa}$

With the fuel injector used, changing the amount of fuel injected (at an otherwise fixed operating condition) changes only the injection duration and not the initial injection rate. Since the current study is concerned only with events up through the first part of combustion, a relatively low fuel load (average equivalence ratio of 0.25 ) was used to minimize window fouling.

To study the effect of TDC air temperature and density on the penetration of the liquid-phase fuel, the intake air temperature and pressure were varied systematically around the base values. The motored-engine TDC temperature was varied from 800 to $1100 \mathrm{~K}$ in approximately $100 \mathrm{~K}$ increments 
by varying the intake air temperature from 349 to $480 \mathrm{~K}$ (assuming a polytropic coefficient of 1.36). As TDC temperature was varied, the TDC density was maintained at a constant value of $16.6 \mathrm{~kg} / \mathrm{m}^{3}$ by adjusting the intake air pressure. Table 5 summarizes the operating parameters for the variations in TDC temperature.

TABLE 5. Operating Conditions for TDC Temperature Variations

\begin{tabular}{ccccc}
\hline Case & $\begin{array}{c}T_{\text {TDC }} \\
{[\mathrm{K}]}\end{array}$ & $\begin{array}{c}\rho_{\text {TDC }} \\
{\left[\mathrm{kg} / \mathrm{m}^{3}\right]}\end{array}$ & $\begin{array}{c}T_{\text {ht }} \\
{[\mathrm{K}]}\end{array}$ & $\begin{array}{c}P_{\text {ht }} \\
{[\mathrm{kPa}]}\end{array}$ \\
\hline T1 & 800 & 16.6 & 349 & 166 \\
T2 & 900 & 16.6 & 393 & 187 \\
BASE & 992 & 16.6 & 433 & 206 \\
T3 & 1100 & 16.6 & 480 & 229 \\
\hline
\end{tabular}

To simulate the effect of turbocharger boost, the intake air pressure was varied from 138 to $413 \mathrm{kPa}$ absolute to obtain motored-engine TDC densities from 11.1 to $33.2 \mathrm{~kg} / \mathrm{m}^{3}$. For this study the intake air temperature was kept constant at $433 \mathrm{~K}\left(160^{\circ} \mathrm{C}\right)$ to maintain a constant TDC temperature of $992 \mathrm{~K}$. These TDC densities correspond to intake air pressures of 0.67 to 2.0 atmospheres absolute for the production version of this engine which has a 16:1 compression ratio. Because they provide convenient units, the data will be presented in terms of these simulated intake pressures. These operating parameters are summarized in Table 6.

TABLE 6. Operating Conditions for TDC Density Variations

\begin{tabular}{cccccc}
\hline Case & $\begin{array}{c}T_{T D C} \\
{[\mathrm{~K}]}\end{array}$ & $\begin{array}{c}\rho_{\text {TDC }} \\
{\left[\mathrm{kg} / \mathrm{m}^{3}\right]}\end{array}$ & $\begin{array}{c}T_{\text {int }} \\
{[\mathrm{K}]}\end{array}$ & $\begin{array}{c}P_{\mathrm{ht}} \\
{[\mathrm{kPa}]}\end{array}$ & $\begin{array}{c}P_{\text {ht }}(\text { C.R.=16:1) } \\
{[\text { atm. absolute] }}\end{array}$ \\
\hline P1 & 992 & 11.1 & 433 & 138 & 0.67 \\
BASE & 992 & 16.6 & 433 & 206 & 1.0 \\
P2 & 992 & 24.9 & 433 & 309 & 1.5 \\
P3 & 992 & 33.2 & 433 & 413 & 2.0 \\
\hline
\end{tabular}

This test matrix was designed to cover most of the operating range typically encountered in Diesel engine design and a few additional points to establish trends and provide data for model verification. Real engine TDC temperatures can vary significantly depending on ambient conditions, engine temperature, and amount of intercooling. Factors affecting TDC density are altitude and turbocharger boost. Typical production turbochargers on the $\mathrm{N}$-series engine boost the intake air pressure by as much as a factor of 3 , giving an intake pressure of 3 atmospheres absolute at sea level. Physical limitations of our experimental system did not allow simulated turbocharger boosts greater than 2 atmospheres absolute, so the range of conditions studied $(0.67$ to $2.0 \mathrm{~atm}$.) might be considered to simulate a truck running at high altitude. Although additional data points would add value, the range of conditions studied here produced substantial changes in liquid-phase fuel penetration and are sufficient to establish the significant trends in the Diesel operating regime.

\section{OPTICAL SETUP}

The penetration of the liquid phase fuel was measured via elastic scattering of the liquid phase using the light sheet of a frequency-doubled ( $532 \mathrm{~nm}) \mathrm{Nd:YAG}$ laser. The beam was formed into a sheet with a combination of cylindrical and spherical lenses. The laser sheet was directed through one of the windows at the top of the cylinder wall and a cut out in the rim of the combustion bowl which were in line with one of the fuel jets. The sheet was oriented at an angle of $14^{\circ}$ upward from horizontal, so that it approached the fuel jet along its axis as shown in Figs. 1 and 2.

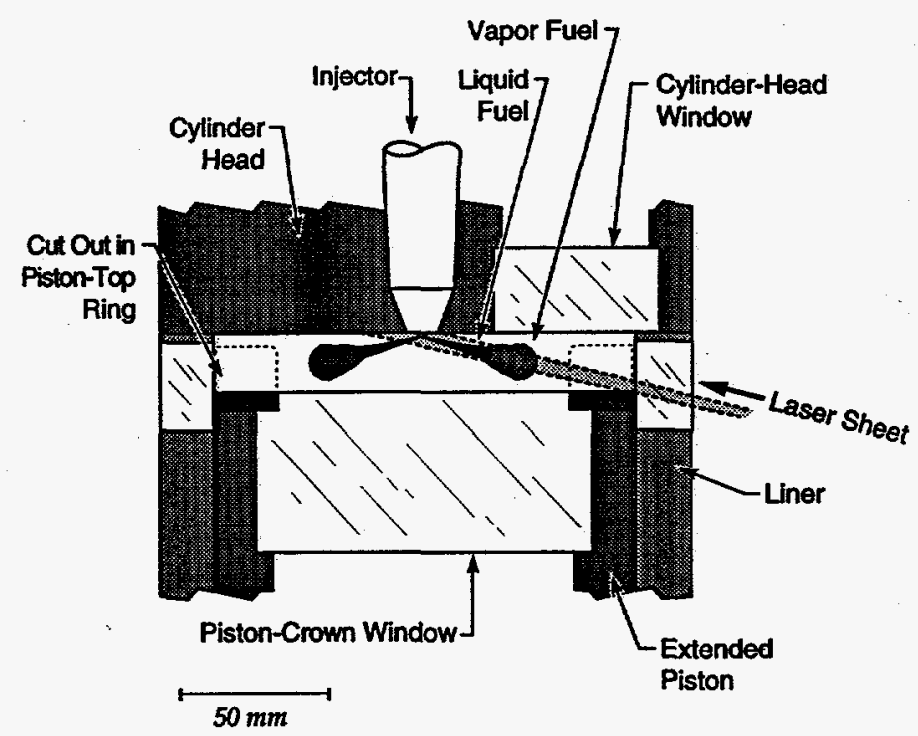

Figure 2. Detailed schematic of the combustion chamber showing the orientation of the thick laser sheet relative to the fuel jet.

Generally, two dimensional laser light sheet experiments are optimized for a minimum sheet thickness. However, in this study the objective was to obtain the maximum axial extension of the liquid-phase fuel. Therefore, the laser sheet was intentionally made relatively thick. The sheet was set up so that it was slightly expanding to clear the edge of the cut out in the combustion bowl at TDC as shown in Fig. 2. In this configuration, the sheet thickness ranged from 5 to $6 \mathrm{~mm}$ in the combustion chamber. The laser sheet was about $20 \mathrm{~mm}$ wide with an energy of about $100 \mathrm{~mJ}$ per pulse.

The images were collected through the piston-crown window by a gated, intensified, CCD video camera. A 532 $\mathrm{nm}$ narrow-band-pass filter $(10 \mathrm{~nm}$ full width at half maximum) was placed in front of the camera to isolate the elastically scattered laser light. Additionally, neutral density filters were used to attenuate the strong Mie scatter signal to an appropriate level.

\section{DATA ACQUISITION}

For all operating conditions cylinder pressure, fuel injection pressure, and injector needle lift data were digitized and recorded at half crank-angle-degree increments and ensemble-averaged over 20 engine cycles. The apparent heat release rate was calculated from the ensemble-averaged cylinder pressure data using the typical first law and perfect gas 
analysis (see for example Heywood [31]). Prior to calculating the apparent heat release rate, the ensemble-averaged pressure data were smoothed with a Fourier series high-frequency-reject filtering algorithm that used a Gaussian roll-off function. Considerable effort was spent in comparing the apparent heat release rates calculated with no filtering and those calculated with various cutoff frequencies and roll-off functions to insure that the filtering algorithm selected removed only the worst high-frequency noise without altering the basic shape of the apparent heat release rate curve.

As mentioned in the previous section, the images were acquired using a gated, intensified video camera. The intensifier gatewidth was set to $50 \mathrm{~ns}$ and the camera intensifier gate was synchronized with the $7 \mathrm{~ns}$ laser pulse. The camera had a video chip resolution of 380 by 480 pixels and was digitized by an 8-bit frame grabber in a 386 personal computer to a resolution of 512 by 480 pixels.

Synchronization between the engine, laser, camera, and intensifier gate was controlled by a second personal computer and a digital delay generator, with the master signal coming from the engine shaft encoder. The camera was equipped with a frame-transfer inhibit feature that allowed the video frame acquisition to be synchronized with the engine. This synchronization system could be adjusted to obtain images at any desired crank angle within the half-degree resolution of the shaft encoder. Although each image is time resolved to nanosecond time scales, only one image could be acquired in a given cycle due to speed limitations of the laser and video recording system. Images were acquired in sets of 12, from 12 separate cycles. Each image presented has been subjectively selected as being representative of its respective set.

\section{RESULTS AND DISCUSSION}

The liquid-phase fuel penetration was measured by analyzing images of the elastically scattered laser light. Since the elastic-scatter signal from the liquid fuel droplets is several orders of magnitude greater than that of the fuel vapor or air, the images provide a good measure of where liquid fuel is present and where it is not. This was demonstrated in this Diesel engine and discussed in detail in an earlier work by the authors [24], and it will be briefly reviewed below. A more detailed explanation of elastic scattering by small particles may be found in various textbooks [32-36]. Since there is no net energy exchange in the elastic scattering process, the scattered light has the same wavelength as that of the incident laser, and a $\mathbf{5 3 2}$ narrow-band-pass filter could be used to isolate the elastic scatter signal.

\section{LIQUID-PHASE FUEL PENETRATION FOR THE BASE CONDITION}

First, a detailed discussion of the liquid-fuel penetration rate and data analysis techniques will be presented for the base operating condition. Although this base-condition data set is similar to that presented by the authors and co-workers in a previous work [24], all the data presented here are new. The new images are of higher quality because the liquid fuel is better illuminated by the thick laser sheet shown in Fig. 2 . Also, the images were acquired at half-crank-angle-degree in- tervals, providing better temporal resolution than the earlier data set which had only one-crank-angle-degree resolution. Finally, this detailed presentation of the data for the base condition provides the necessary background for presentation of the parametric variations in TDC temperature and density.

Figure 3 shows a plot of the cylinder pressure, needle lift, and apparent heat release rate for the base operating condition. All three data types are ensemble-averaged over 20 engine cycles. As described above, at this condition, the estimated TDC temperature and density were $992 \mathrm{~K}$ and $16.6 \mathrm{~kg} / \mathrm{m}^{3}$, respectively, for the motored engine. This TDC density is typical of that of a production engine running with an intake pressure of 1 atmosphere (no turbocharger boost). It should be noted that this base operating condition is the same condition used by the authors in several previous studies involving quantitative vapor-fuel concentration measurements $[24,25,37]$, relative soot concentrations and particle size measurements [28-30], and ignition data [29].

As typically found in Diesel combustion, the apparent heat release rate curve in Fig. 3 first goes negative just after the start of fuel injection because of the apparent heat loss due to fuel vaporization. Then, after a few degrees, the combustion energy release exceeds that required for vaporizing the fuel, and the apparent heat release rises rapidly. Although the authors have shown by chemiluminescence imaging [29] that "ignition" actually begins prior to this rapid rise in the apparent heat release rate curve, the onset of the rapid rise provides a convenient repeatable point for comparing various data sets. This point, which will be referred to as the first indicated heat release, occurs at $-7.5^{\circ}$ ATDC for the base condition, ${ }^{*}$ as indicated by the edge of the light gray shaded area in Fig. 3. For this study, we define ignition delay to be the time from the first indication of injector needle lift $\left(-11.5^{\circ}\right.$ ATDC) to the point of the first indicated heat release.

Figure 4 shows a temporal sequence of liquid-phase fuel images obtained at the base operating condition (Table 4). As discussed in the subsection on data acquisition, each of these images (as with all images presented) is from a separate engine cycle, and has been subjectively selected from sets of 12 images from 12 different engine cycles at each crank angle. We believe that they represent typical liquid-phase fuel distributions for their respective crank angles, and as such, they can be compared with the corresponding ensemble-averaged plots of the cylinder pressure, needle lift, injection pressure, and apparent heat release rate.

The fuel images in Fig. 4 were acquired through the piston-crown window. In each image the location of the injector tip is evident at the center of the 8 fuel jets, and the gray curve at the right marks the edge of the combustion bowl (see Figs. 1 and 2). The horizontal distance from the injector to the edge of the bowl is $49 \mathrm{~mm}$, and the number at the upper right of each image gives the crank angle degree after the

\footnotetext{
* In previous works by the authors $[24,25,28-30,37]$, a different filtering algorithm was used to reduce the cylinder pressure data to apparent heat release rate. This caused some small differences in the apparent heat release rate curve for the base condition. As a result, the first indicated heat release was taken to be $-7.0^{\circ}$ ATDC in these previous studies.
} 


$$
\begin{aligned}
& \text { - Heat Release Rate } \\
& \text {-..-- Cylinder Pressure } \\
& \text {-.- Needle Lift }
\end{aligned}
$$

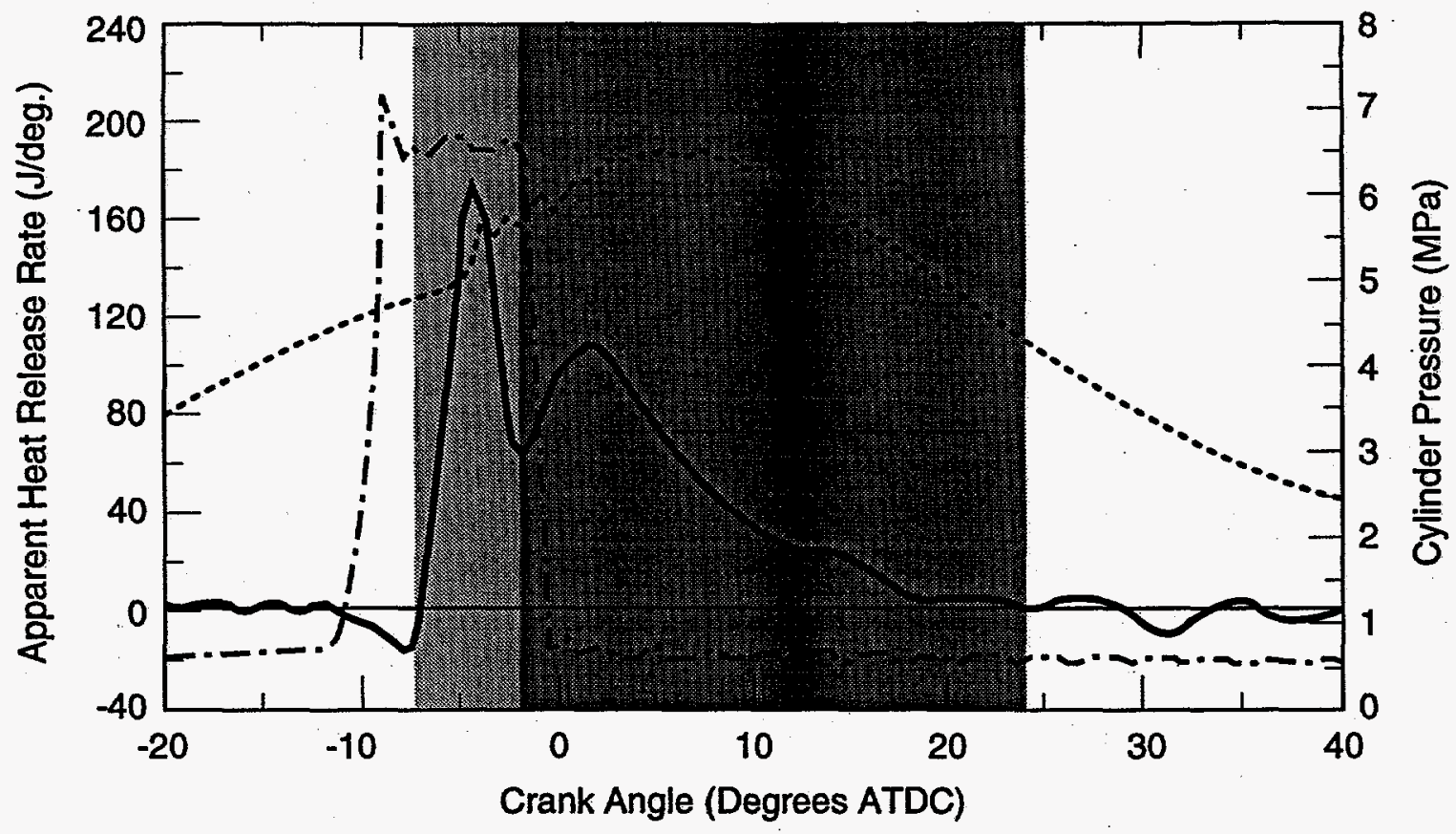

Figure 3. Heat release rate, cylinder pressure, and injector needle lift for the base operating condition (TDC temperature $=992 \mathrm{~K}$, TDC density $=16.6 \mathrm{~kg} / \mathrm{m}^{3}$ ). Data are ensemble-averaged over 20 cycles.

start of injection (ASI). The fuel spray is angled downward $14^{\circ}$ from horizontal, and the laser sheet enters the field of view from the right along the axis of the fuel jet in the 3 o'clock position (see Figs. 2 and 4). Initially all eight fuel jets are fairly well illuminated, and the liquid-fuel distribution between the jets may be seen to be quite uniform. Although a previous investigation [28] has shown that all eight fuel jets remain very symmetric throughout the combustion event, after about $2.0^{\circ}$ ASI the jets do not appear uniform in Fig. 4 because the tips of most of the jets have traveled outside of the laser sheet and are no longer well illuminated. Only the fuel jet in the 3 o'clock position is well illuminated throughout the sequence, and it is this jet in which the liquid-fuel penetration length measurements are made.

Following the image sequence in Fig. 4, it can be seen that fuel injection has not yet begun in the image labeled $0^{\circ}$ ASI (-11.5 ATDC). This image corresponds to the timing of the start of first injector-needle motion. Injection actually starts sometime during the half-crank-angle degree $(70 \mu \mathrm{s})$ interval between this image and the second image of the sequence which shows liquid fuel extending about $2.5 \mathrm{~mm}$ into the combustion chamber. Then, for the next 3 degrees, the extent of the liquid fuel increases rapidly reaching a length of about half the bowl radius (approximately $23 \mathrm{~mm}$ ) by $3^{\circ} \mathrm{ASI}$ (-8.5 ATDC). Beyond $3^{\circ}$ ASI, the liquid length remains fairly constant at about $23 \mathrm{~mm}$.

Before analyzing these images to determine the liquidfuel penetration length, it is necessary to verify that no liquid fuel exists downstream of the high-intensity region in the
3 o'clock jet. The images show that around the leading edge of the 3 o'clock jet, the elastic-scatter signal drops rapidly from the relatively high levels in the fuel jet down to the background level. Increasing the signal intensity by opening the camera aperture increased the magnitude of the liquidfuel signal to near the damage threshold of the camera, but failed to show any increase in the liquid length. This indicates that beyond the liquid region evident in Fig. 4, the jet consists of purely vapor-phase fuel (mixed with air), and not just smaller fuel droplets. A rigorous proof of this characteristic feature of Diesel fuel jets has been presented by the authors and co-workers in a previous work [24]. This was done by obtaining high-magnification elastic-scatter images of the Diesel fuel jet and evaluating the signal intensities of droplets and solid particles of progressively smaller sizes to determine the resolution of the imaging system. Beyond $27 \mathrm{~mm}$ (along the nominal fuel-jet axis) from the injector all the fuel was shown to be entirely vapor phase.

The liquid-fuel penetration length was obtained from the elastic-scatter images using a computerized analysis algorithm. Each of the 12 images at each crank angle was scanned row by row to determine the maximum rightward extent of the high intensity region. As evident in Fig. 4, this always corresponds to the tip of the 3 o'clock fuel jet. Inherent in any technique for analyzing these images is the selection of a threshold intensity for the extent of the liquid phase. After manually checking several images a threshold intensity of $\mathbf{5 0}$ was selected. Note that because an 8-bit frame grabber was used, intensities of 0 and 255 correspond to totally black and 


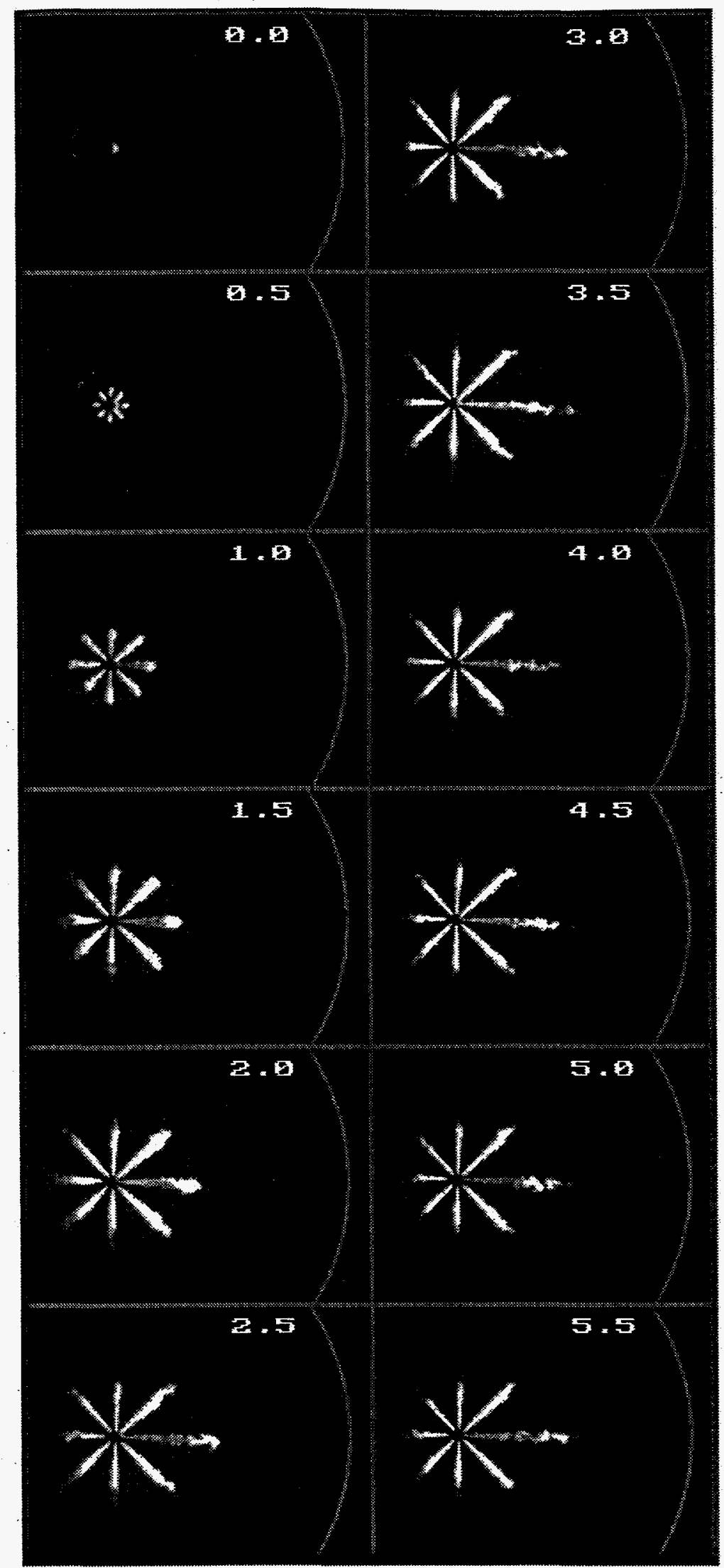

Figure 4. Temporal sequence of elastic-scatter liquid-fuel images for base condition (TDC temperature $=992 \mathrm{~K}$, TDC density $=$ $16.6 \mathrm{~kg} / \mathrm{m}^{3}$ ). The laser sheet propagates from right to left up the axis of the jet in the 3 o'clock position as shown in Fig. 2. All eight fuel jets are visible; however, only the jet in the 3 o'clock position is fully illuminated. The curve at the right of each image shows the edge of the combustion bowl. 
totally white, respectively. Although the selection of 50 as the threshold intensity was somewhat arbitrary, the liquid lengths were not very sensitive to the exact value used because of the rapid drop off in signal at the tip of the jet. Varying the threshold by 30 or more counts only shifted the measured liquid length slightly and was not sufficient to change any of the findings presented here. After determining the maximum extent of the liquid fuel in the images, which are horizontal projections of the fuel jet, the measurement was converted to millimeters along the nominal fuel jet axis (14 ${ }^{\circ}$ downward from horizontal).

A plot of the maximum liquid-fuel penetration (along the fuel jet axis) with crank angle is shown in Fig. 5a. This plot shows data from all of the 12 images which were acquired at each crank angle." The solid line is a cubic spline fit to the data. Although there is some spread in the data due to cycle-to-cycle variation, the trend is consistent. Initially, the liquid fuel penetrates almost linearly with increasing crank angle, as observed in other studies at room temperature [38], until it reaches a maximum length of about $23 \mathrm{~mm}$ at 3.0 to $3.5^{\circ} \mathrm{ASI}\left(-8.5\right.$ to $\left.-8.0^{\circ} \mathrm{ATDC}\right)$. The liquid length then remains nearly constant even though fuel injection continues until $10.5^{\circ}$ ASI ( $-1.0^{\circ}$ ATDC), as shown by the injector needle lift record in Fig. 5b. Therefore, virtually all fuel must be vaporized by the time it reaches a distance of $23 \mathrm{~mm}$ from the injector. These results are in agreement with previous studies by the authors $[23,24]$ and with studies by Kamimoto et al. [10] and Browne et al. [5] that also indicated a limited liquid penetration. Finally, although fuel injection continues until $10.5^{\circ}$ ASI $\left(-1.0^{\circ}\right.$ ATDC), the liquid penetration data are not presented beyond $7.0^{\circ}$ ASI (-4.5 $5^{\circ}$ ATDC) because soot from combustion began to obscure the images.

A comparison of apparent heat release rate in Fig. 3 with the liquid-fuel penetration plot in Fig. 5a. shows that the first indicated heat release does not begin until $-7.5^{\circ}$ ATDC (4.0 $0^{\circ}$ ASI). This is a full crank-angle degree after the liquid fuel has reached its maximum penetration. Accordingly, the limited liquid-phase fuel penetration is not a result of combustion heating, but is due solely to the evaporation induced by entrainment of hot (heated by compression) ambient air into the fuel jet.

\section{THE EFFECT OF TDC TEMPERATURE ON LIQUID- PHASE FUEL PENETRATION}

The liquid-fuel penetration length is determined by the rate of vaporization of the fuel. For the base condition, the energy content of the in-cylinder air (air temperature of $992 \mathrm{~K}$ ) and the mixing rate of the air with the liquid fuel were such that all the fuel vaporized by the time it traveled about $23 \mathrm{~mm}$ from the injector. In order to separate the effects of air temperature and air density, which can significantly impact the mixing rate of fuel and air, ${ }^{* *}$ each parameter was

\footnotetext{
* Some data points in the top of Fig. 5 fall in the same location as other points resulting in less than 12 visible data points at each crank angle.

* It is recognized that other parameters such as fuel-injection pressure and in-cylinder air motion can also have a large effect on fuelair mixing; however, these parameters were not investigated here.
}
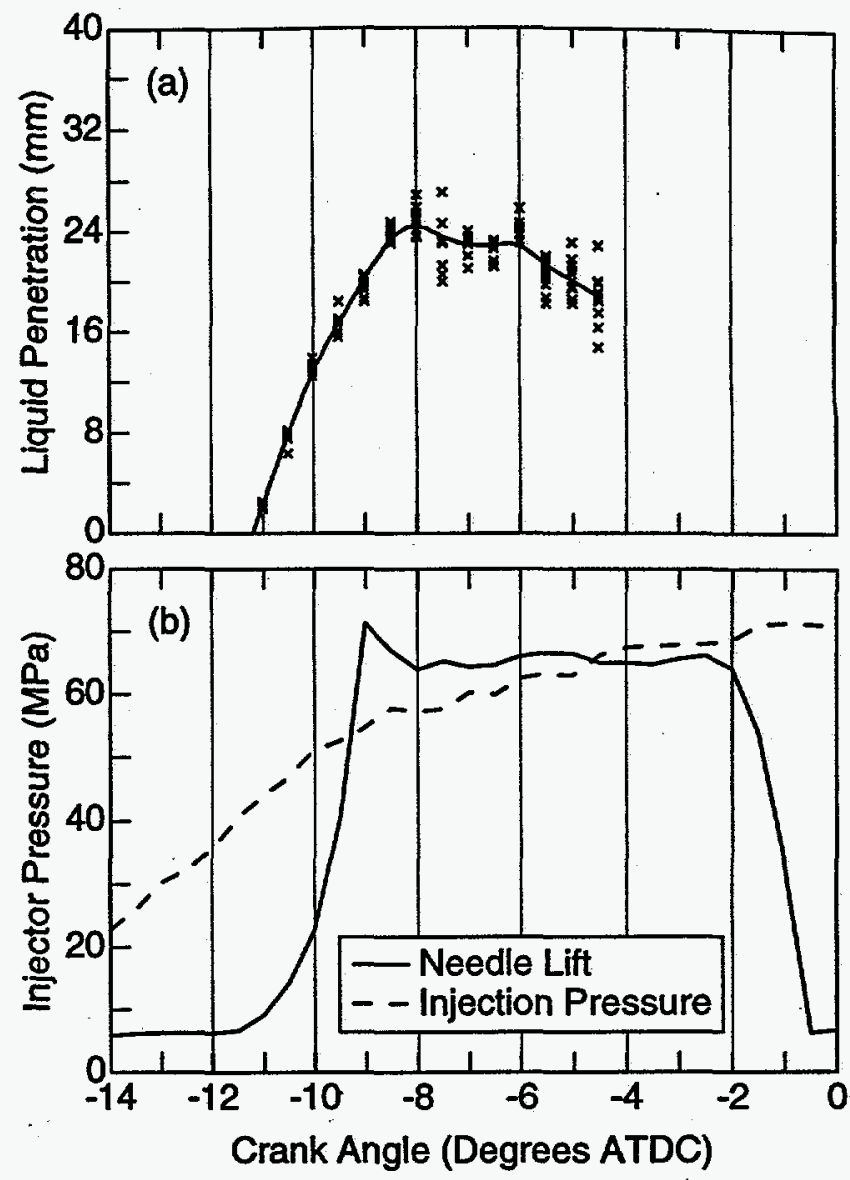

Figure 5. Liquid-phase fuel penetration (Fig. 5a) and injector needle lift and injection pressure (Fig. $5 \mathrm{~b}$ ) for the base condition (TDC temperature $=992 \mathrm{~K}$, TDC density $=16.6 \mathrm{~kg} / \mathrm{m}^{3}$ ). Figure 5 a shows the data points from 12 cycles at each crank angle and a cubic spline fit to the data. The data in Fig. $5 \mathrm{~b}$ are ensemble-averaged over 20 cycles.

varied systematically while the liquid-fuel penetration length was measured using elastic-scatter imaging.

The TDC temperature was varied in approximately 100 $\mathrm{K}$ increments from $800 \mathrm{~K}$ to $1100 \mathrm{~K}$ for a constant density of $16.6 \mathrm{~kg} / \mathrm{m}^{3}$. Table 5 shows these TDC conditions and the intake air temperatures and pressures used to achieve them. At each operating condition, 12 liquid-fuel images were taken at half-crank-angle degree increments from the start of injection to the time when soot from the combustion process obscured the image. Because ignition delay varied significantly for the various temperatures, as discussed below, the onset of soot formation also varied, allowing liquid images to be acquired for a longer time period at the cooler temperatures.

Using the computerized processing algorithm, the distance from the injector to the tip of the liquid-phase was measured in each image. Then, for each temperature, these liquid-length data were plotted and fit to a cubic spline curve in the same manner shown for the base condition in Fig. 5a. The four plots showing all the data and the spline fit for each temperature are presented in the Appendix (Fig. A1). For the comparison of the four temperatures presented in Fig. 6, only the cubic spline curves are shown to avoid the clutter of all the data points. 


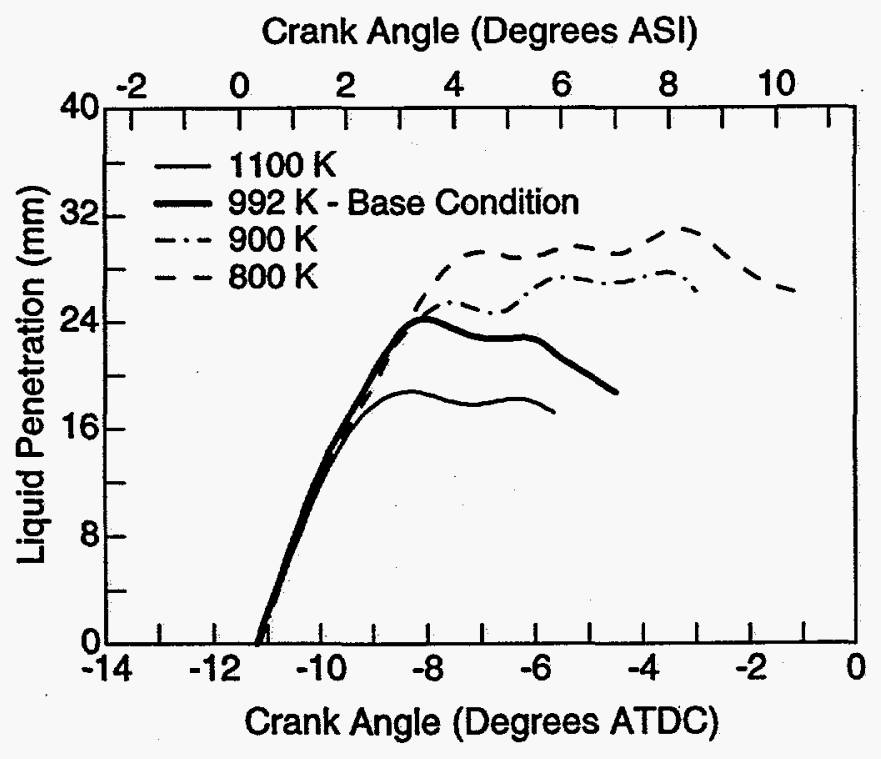

Figure 6. Liquid penetration for various TDC temperatures at a constant TDC density of $16.6 \mathrm{~kg} / \mathrm{m}^{3}$. The curves are cubic spline fits to the data. For each TDC temperature, the raw data and curve fit are given in the Appendix.

The curves in Fig. 6 show how the liquid-fuel penetration varies with TDC air temperature at constant density. For all four temperatures, the initial liquid fuel penetration rate is almost linear, and the rate is virtually identical for all temperatures examined. Then, each curve breaks over and the liquid length remains almost constant although fuel injection continues through the entire time period of the liquid-length measurements. The fuel injection rate and duration were the same for all conditions and does not end until $10.5^{\circ}$ ASI $\left(-1^{\circ}\right.$ ATDC), as shown in Fig. 5b.

Although the basic shape of all the curves in Fig. 6 is qualitatively the same, they show a clear trend with TDC temperature. The time to reach maximum penetration and the maximum liquid-penetration length both systematically decrease with increasing TDC temperature. Maximum liquid penetration lengths vary from about $30 \mathrm{~mm}$ at $800 \mathrm{~K}$ to about $18 \mathrm{~mm}$ at $1100 \mathrm{~K}$ (see also Fig. 9).

Typical liquid-fuel images taken just after the knee (break-over point) in the liquid fuel penetration curves are presented in Fig. 7 for the four temperatures. They clearly show a decrease in the liquid-phase fuel penetration length with increasing temperature, consistent with the curves in Fig. 6.

In addition to changes in the liquid-fuel penetration length, changing the TDC temperature produced systematic changes in the ignition delay and premixed burn fraction. Figure 8 shows the apparent heat release rate curves for the four TDC temperatures. Also shown is a typical injector needle-lift trace that identifies the start of injection and the injection duration, which was the same for all four conditions. As might be anticipated, Fig. 8 shows the shortest ignition delay (3.0 crank angle, $\mathrm{CA}$ ) for $1100 \mathrm{~K}$ and the delay time progressively increasing with decreasing temperature up to the longest ignition delay $\left(8.5^{\circ} \mathrm{CA}\right)$ at $800 \mathrm{~K}$. Corresponding

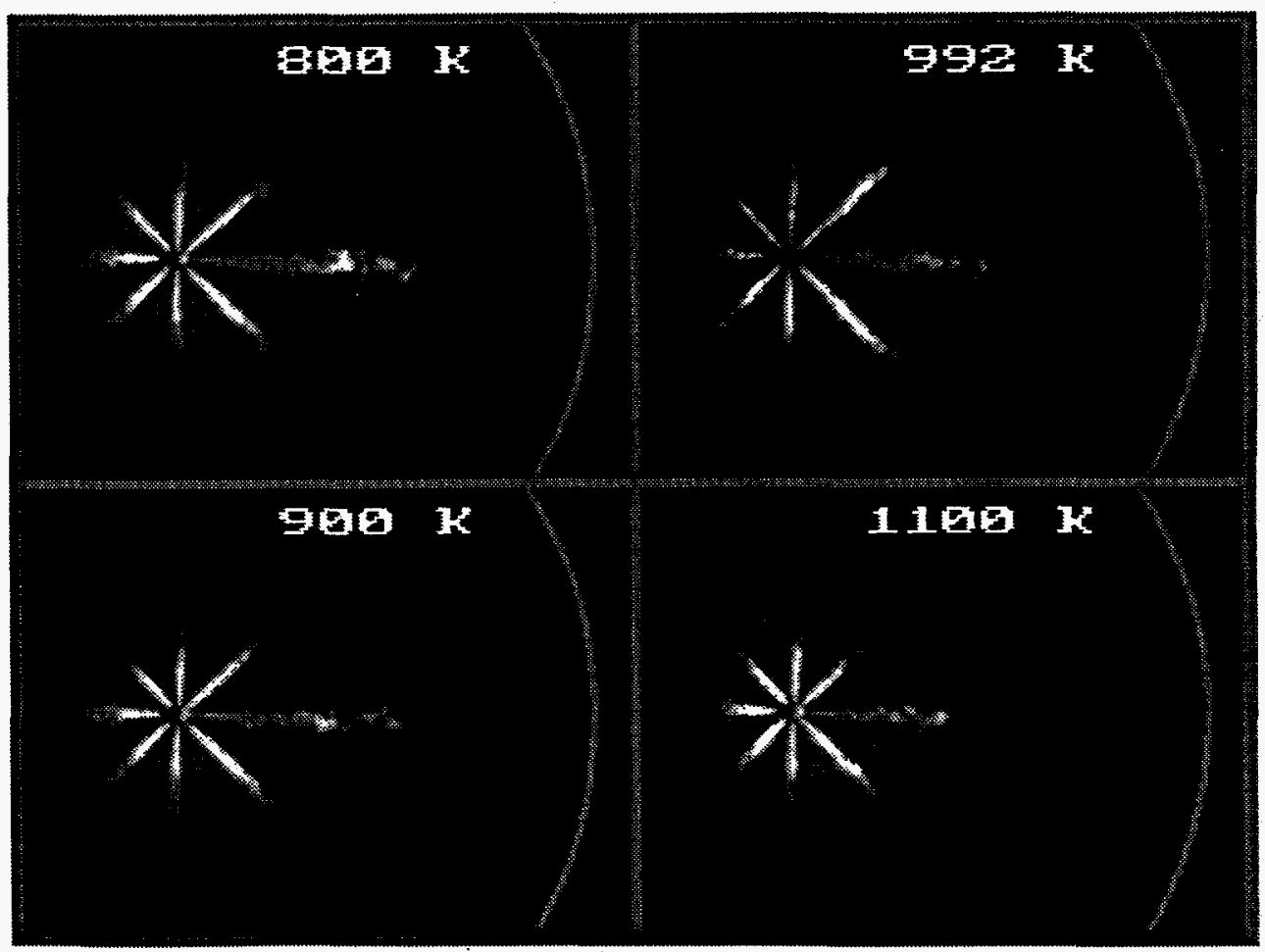

Figure 7. Typical maximum-penetration liquid-phase fuel images for the various TDC temperatures (see Table 5). The laser sheet propagates from right to left up the axis of the jet in the 3 o'clock position as shown in Fig. 2. All eight fuel jets are visible; however, only the jet in the 3 o'clock position is fully illuminated. The curve at the right of each image shows the edge of the combustion bowl. The horizontal distance from the injector to combustion bowl is about $49 \mathrm{~mm}$. 
Crank Angle (Degrees ASI)

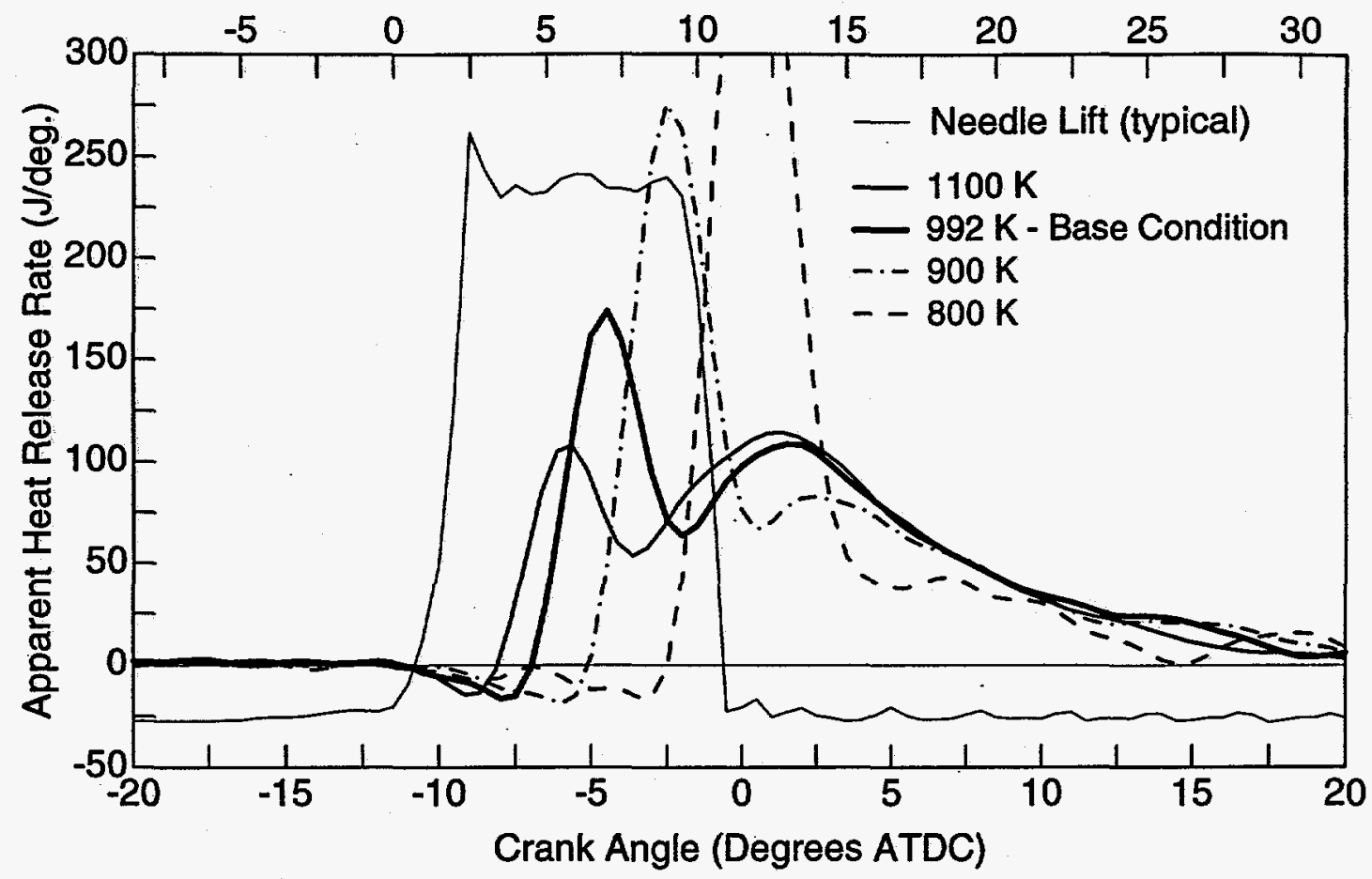

Figure 8. Apparent heat release rate for various TDC temperatures at a constant TDC density of $16.6 \mathrm{~kg} / \mathrm{m}^{3}$. Also shown is a typical fuel-injector needle lift curve to show the start and end of injection. For each condition the individual apparent heat release rate, cylinder pressure and needle lift curves are given in the Appendix.

to these changes in ignition delay time, the premixed burn fraction increases from a minimum at $1100 \mathrm{~K}$ to a maximum at $800 \mathrm{~K}$. In addition to the heat release rate comparison shown in Fig. 8, separate graphs showing cylinder pressure, needle lift, and apparent heat release rate for each of the four temperatures are given in the Appendix (Fig. A1).

Figure 9 summarizes the effect of TDC temperature on the maximum liquid-phase fuel penetration and the ignition delay. The maximum liquid lengths in this figure are averages of all the data points from just after the break-over point in the liquid-fuel penetration curve up to near the end of the observation period." For each TDC temperature, the ignition delay is taken to be the time from the first indicated injector needle lift $\left(-11.5^{\circ}\right.$ ATDC) up to the point that the heat release rate curve beings its rapid rise. The decrease in both maximum liquid length and ignition delay with increasing TDC temperature is clearly evident in the figure.

A comparison of the apparent heat release rates in Fig. 8 (and the Appendix) with the liquid-fuel penetration curves in Fig. 6 shows that the maximum liquid-fuel penetration is reached prior to significant combustion heat release. For the 800,900 , and $992 \mathrm{~K}$ cases, the initial rise of the heat release rate occurs well after maximum liquid penetration is reached. For the $1100 \mathrm{~K}$ case, the ignition delay is very short, and

\footnotetext{
* As discussed in the subsection entitled Discussion of Results, the liquid lengths for all conditions become slightly less near the end of the observation period. Since this may be a result of soot obscuration, the data points at these crank angles were not included in computing the average maximum liquid lengths in Figs. 9 and 13.
}

maximum liquid penetration is reached just as the heat release is starting. However, the amount of heat released by this time is barely enough to overcome the energy lost to fuel vaporization, so its impact on the maximum penetration length would be negligible. Thus, the liquid-fuel penetration length shown here is limited strictly by the entrainment of the hot in-cylinder air into the liquid spray, and it is not the result of combustion heating.

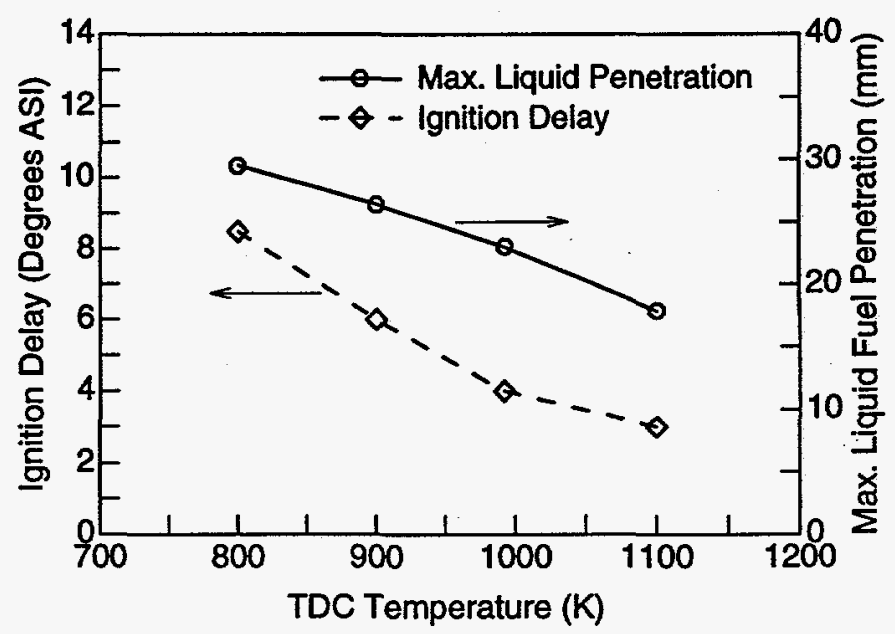

Figure 9. Ignition delay and maximum liquid-fuel penetration for various TDC temperatures at a constant TDC density of $16.6 \mathrm{~kg} / \mathrm{m}^{3}$. 
THE EFFECT OF TDC DENSITY ON LIQUID-PHASE FUEL PENETRATION

In Diesel engines the TDC air density can vary by a factor of $\mathbf{2}$ or $\mathbf{3}$ from naturally aspirated conditions up to full turbocharger boost on the intake. Changes in the air density can significantly impact the mixing rates of air with the liquidphase fuel both by changing the droplet breakup rate and by changing the amount of air entrainment into the spray and hence the energy available for fuel vaporization. These effects of changing air density will impact the liquid-phase fuel penetration.

As previously discussed in the subsection on Operating Conditions, the intake conditions were varied from effective turbocharger boost conditions from 0.67 to 2.0 atmospheres* (TDC densities of 11.1 to $33.2 \mathrm{~kg} / \mathrm{m}^{3}$ ), for a constant TDC temperature of $992 \mathrm{~K}$. A complete list of the intake conditions and corresponding TDC densities are given in Table 6. As with the variation in TDC temperature, for each condition, 12 images were acquired and analyzed at each half-crankangle degree from the start of injection up to the point where soot obscured the images. For all four TDC densities, these liquid-fuel penetration data and the cubic spline fits to the data are presented in the Appendix (Fig. A2), along with plots of the apparent heat release rate, cylinder pressure, and needle lift.

Figure 10 shows the cubic-spline-fit curves of the liquid penetration for the four TDC density conditions studied. The general shapes of the curves are similar to those in Fig. 6, discussed above. The initial liquid fuel penetration rate is almost linear and virtually identical for all four densities examined. Then, there appears to be a slight, but consistent, trend of a decreasing rate of penetration with increasing density, leading up to the point where the curves break over. Beyond the break-over point, these data show a very strong trend of a decreased maximum liquid-fuel penetration length with increasing TDC density. The maximum liquid penetration lengths vary from about $30 \mathrm{~mm}$ for $11.1 \mathrm{~kg} / \mathrm{m}^{3}(0.67 \mathrm{~atm}$. intake) to about $13 \mathrm{~mm}$ for $33.2 \mathrm{~kg} / \mathrm{m}^{3}$ (2.0 atm. intake).

Similar to Fig. 7, Fig. 11 presents typical liquid-fuel images for the four TDC densities taken just after the knee (break-over point) in the liquid fuel penetration curves. The significant decrease in liquid length with increasing TDC density is also evident in these images.

The apparent heat release rates for the four TDC densities are shown in Fig. 12. As with changes in TDC temperature, changes in TDC density cause systematic changes in the ignition delay and premixed burn fraction. As TDC density is increased, the ignition delay and premixed burn fraction progressively decrease, with ignition delays varying from $7.5^{\circ} \mathrm{CA}$ at $11.1 \mathrm{~kg} / \mathrm{m}^{3}$ to $1.5^{\circ} \mathrm{CA}$ at $33.2 \mathrm{~kg} / \mathrm{m}^{3}$.

These changes in ignition delay and the changes in maximum liquid-fuel length with TDC density are summarized in Fig. 13. The liquid lengths and ignition delays presented were calculated in the same manner as those in Fig. 9.

\footnotetext{
* As discussed in the Operating Conditions subsection, the intake pressures of 0.67 to 2.0 atmospheres correspond to those that would be required for a 16:1 compression ratio production engine to reach the same TDC densities used here. The actual intake pressures were higher because of the 10:1 compression ratio of the optical-access research engine, as shown in Table 6.
}

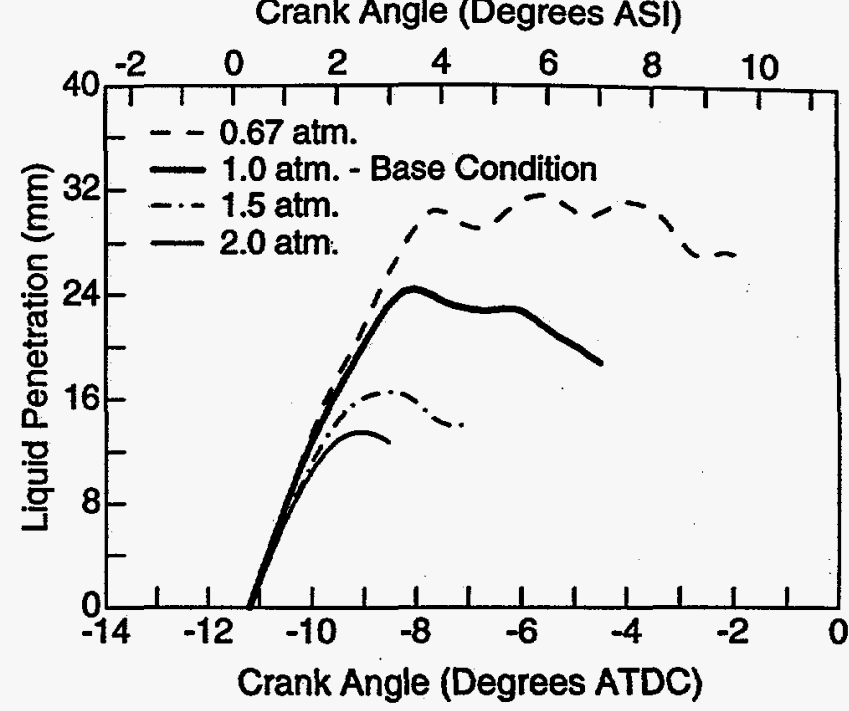

Figure 10. Liquid penetration for various densities at constant temperatures. The curves are cubic spline fits to the data. For each intake pressure (TDC density), the raw data and curve fit are given in the Appendix.

The decrease in both maximum liquid length and ignition delay with increasing TDC density is clearly evident in the figure.

A comparison of Figs. 10 and 12 shows that for all densities except the highest $\left(33.2 \mathrm{~kg} / \mathrm{m}^{3}\right)$, the liquid-fuel penetration reaches its maximum value before significant heat release has occurred. For these conditions, the combustion heating does not impact the maximum liquid penetration length. At the highest density $\left(33.2 \mathrm{~kg} / \mathrm{m}^{3}\right)$, heat release starts within $1.5^{\circ}$ ASI and maximum penetration is not reached until $2.0^{\circ}$ to $2.5^{\circ}$ ASI. However, even by $2.5^{\circ}$ ASI $\left(-9^{\circ}\right.$ ATDC) the total heat released is very small and it is unlikely that it has a significant impact on the liquid length. Accordingly, the changes in vaporization rate, and the corresponding changes in maximum liquid-penetration length, observed for the various TDC densities, are caused by the entrainment of the hot in-cylinder air into the liquid spray, as was the case for the various TDC temperatures.

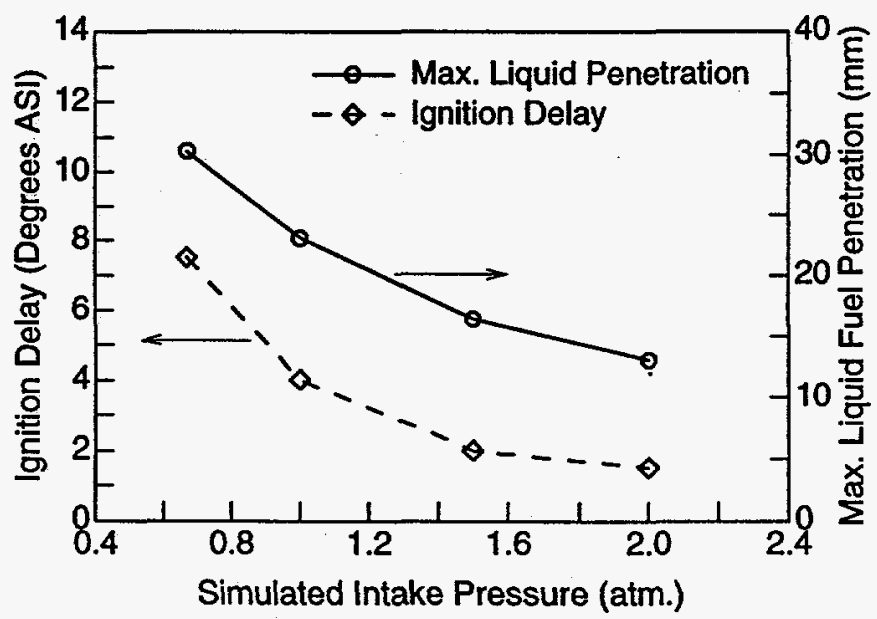

Figure 13. Ignition delay and maximum liquid-fuel penetration for various TDC densities (simulated intake pressures) at a constant TDC temperature of $992 \mathrm{~K}$. 


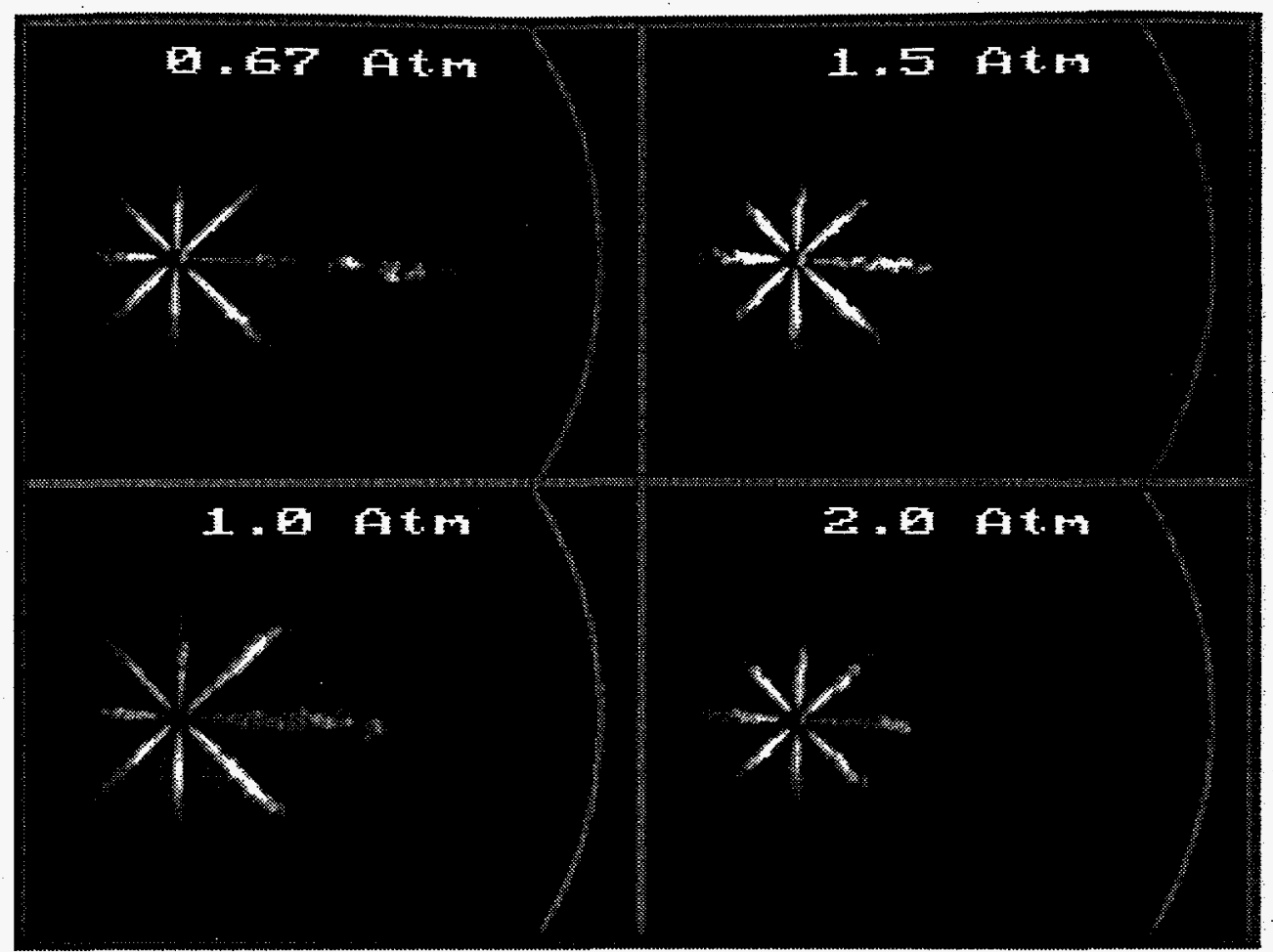

Figure 11. Typical maximum-penetration liquid-phase fuel images for the various simulated intake pressures (TDC densities, see Table 6). The laser sheet propagates from right to left up the axis of the jet in the 3 o'clock position as shown in Fig. 2 . All eight fuel jets are visible; however, only the jet in the $3.0^{\prime}$ clock position is fully illuminated. The curve at the right of each image shows the edge of the combustion bowl. The horizontal distance from the injector to combustion bowl is about $49 \mathrm{~mm}$.

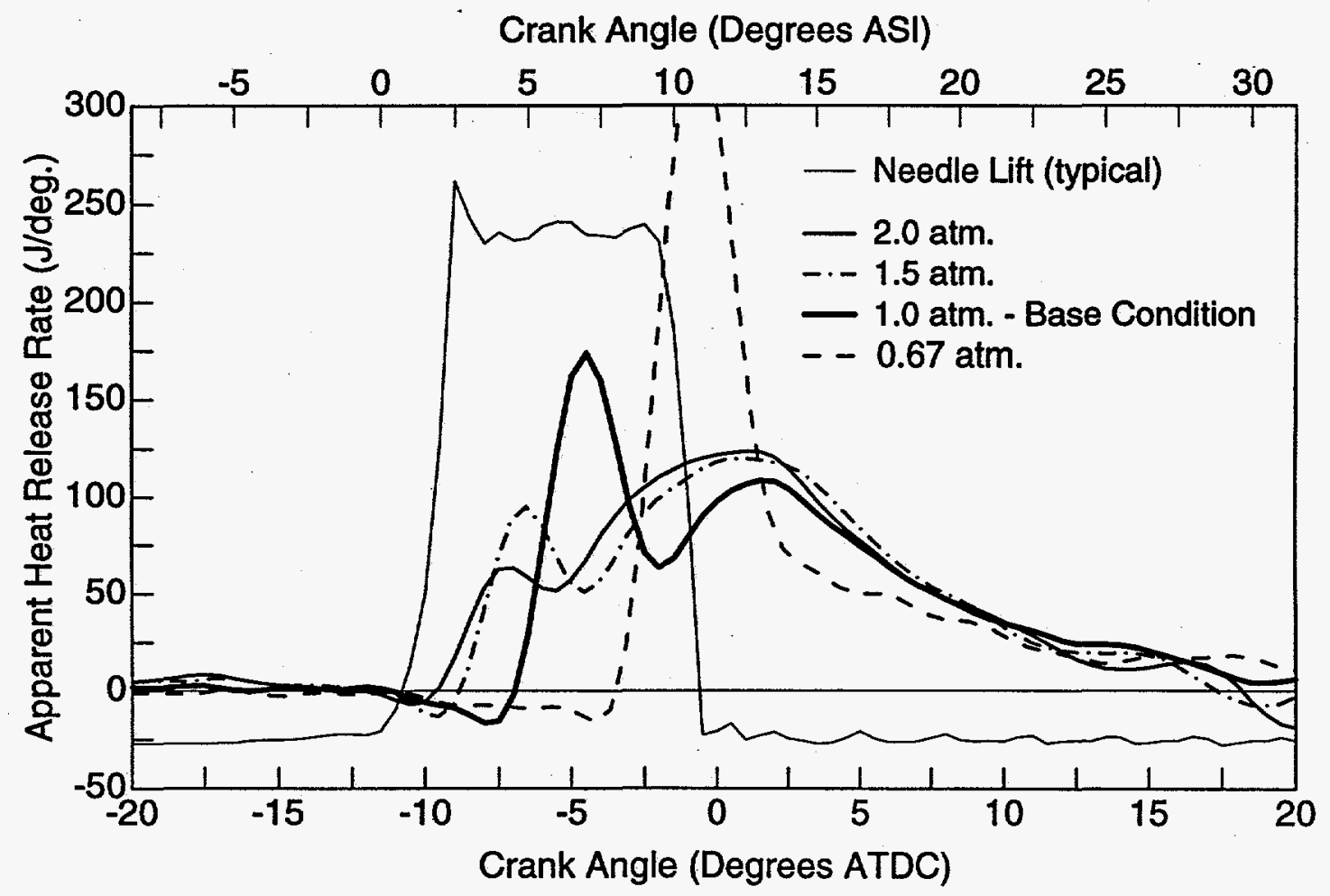

Figure 12. Apparent heat release rate for various simulated intake pressures (TDC densities) at a constant TDC temperature of $992 \mathrm{~K}$. Also shown is a typical fuel-injector needle lift curve to show the start and end of injection. For each condition the individual apparent heat release rate, cylinder pressure and needle lift curves are given in the Appendix. 


\section{DISCUSSION OF RESULTS}

The above data show that changes in TDC temperature and TDC density each independently have a strong effect on both the maximum liquid-fuel penetration length and ignition delay. Also, whether ignition delay is varied by changing TDC temperature or density, variations in ignition delay always correlate with variations in premixed burn fraction.

For changes in TDC temperature, these effects might have been anticipated. Increasing the air temperature increases the energy available to overcome the heat of vaporization of the fuel, thereby increasing the vaporization rate and decreasing the maximum liquid-fuel penetration. Increasing the temperature also increases the chemical kinetic reaction rates, thus decreasing the ignition delay time. Having less time available for fuel-air mixing prior to ignition tends to decrease the amount of premixed fuel available at ignition. However, increasing the vaporization rate of the fuel would tend to increase the mixing rate of fuel and air on a molecular scale, which would have the opposite effect on (it would increase) the amount premixed fuel available at ignition. Since Fig. 8 shows the premixed burn fraction decreasing, clearly the former effect dominates. The reason for this is straightforward, the change in the chemical-kinetic ignition delay time is an exponential function of temperature; while to first order, the increased vaporization rate is expected to be linear with temperature.

Although the data show that changes in TDC density have even more impact on maximum liquid penetration and ignition delay than changes in TDC temperature, the results are perhaps less readily anticipated. The air density affects the maximum liquid penetration in two main ways. First, air density is an important parameter in the breakup of liquid droplets. Higher air densities cause faster breakup rates, which in turn increase fuel-air mixing rates. Second, higher air densities increase the amount of air entrained into the liquid spray. This raises the average mixture temperature and therefore increases the vaporization rate, or on a per droplet basis, the higher-density entrained air has more energy available in a given volume to heat up adjacent fuel droplets. Both of these effects (droplet breakup and entrainment rate) lead to increased vaporization rates at increased TDC air density, as the liquid-fuel penetration data show (Figs. 10 and 13). Changes in the TDC density at constant temperature also affect the ignition delay in two ways. First, similar to the way it increases the vaporization rate, higher density air has more energy content per unit volume, so mixing a given volume of high-density air with the fuel adds more total energy to the mixture. Thus, the mixture temperature is higher, and the chemical-kinetic reaction rates are increased. Second, increasing the density at constant temperature results in increased TDC pressures. Shock tube experiments [39] and kinetic rate computations [40] have shown that at typical Diesel engine temperatures $(800$ to $1100 \mathrm{~K}$ ), the pressure has a fairly strong effect on the ignition delay time. Both of these two effects go in the same direction, and cause a shorter ignition delay with higher TDC densities, as observed in Figs. 12 and 13.
For all the temperature and density conditions measured, the liquid length becomes slightly less at the end of the observation period, just before the image is obscured by soot. For most conditions, this downward trend is within the scatter in the data (see plots in the Appendix). However, the consistency of the trend at all conditions suggest that it may be real. There are two possible explanations for this apparent trend. First, it could simply be the result of optical obscuration due to early soot formation. However, there was no noticeable drop in image intensity at these crank angles as there was at crank angles beyond those presented. Second, it may be a result of combustion heating. This could occur either by direct localized heat transfer, or by compressive heating of the remaining in-cylinder air by the expansion of the combusting gases. The latter would cause an increase in the temperature and density of the air being entrained into the fuel spray, which in turn would increase the vaporization rate and decrease the liquid. length. Additional measurements are needed to resolve this issue of the liquid-penetration length becoming shorter as combustion proceeds.

The range of TDC temperatures and densities examined covers a major portion of the typical warm-engine Diesel operating regime. The exception is that at maximum turbocharger boost, intake pressures often reach the 3 atmosphere range, as opposed to the 2 atmosphere maximum intake pressure studied here. The data presented indicate that an intake pressure of 3 atmospheres would produce an even shorter maximum liquid-fuel penetration length than the $13 \mathrm{~mm}$ length observed for the 2 atmosphere boost condition. Accordingly, these data show that over the typical warm-engine operating range, TDC density has a greater effect on both maximum liquid-fuel penetration and on ignition delay than does TDC temperature.

Finally, even at the coldest and lowest density conditions examined, the maximum liquid-fuel length was only about $30 \mathrm{~mm}$. Although this is much longer than the shortest length observed $(13 \mathrm{~mm})$, it is still less than the injector-towall distance in the production version of this engine. Thus, liquid-fuel wall impingement will not occur in this engine over the range of conditions studied.

\section{SUMMARY AND CONCLUSIONS}

The effect of the TDC temperature and density on the penetration of the liquid-phase fuel was studied in a directinjection Diesel engine using planar elastic-scatter imaging. Measurements were made in a single-cylinder optically accessible Diesel engine derived from a Cummins $\mathrm{N}$-series production engine. For all experiments, the engine was operated at a medium speed of $1200 \mathrm{rpm}$ and a Cummins electronically controlled closed-nozzle fuel injector was used. The base intake air conditions were set so that the motored TDC temperature and density $\left(992 \mathrm{~K}\right.$ and $16.6 \mathrm{~kg} / \mathrm{m}^{3}$ ) as well as ignition delay and premixed burn fraction were similar to those of a naturally aspirated production Cummins $\mathrm{N}$-series Diesel engine.

To study their effects on the liquid-phase fuel penetration, the TDC temperature and density were varied paramet- 
rically around the base condition. By adjusting the intake air temperature and pressure, the TDC temperature was varied from 800 to $1100 \mathrm{~K}$ for a constant TDC density of $16.6 \mathrm{~kg} / \mathrm{m}^{3}$, and the TDC density was varied from 11.1 to $33.2 \mathrm{~kg} / \mathrm{m}^{3}$ for a constant TDC temperature of $992 \mathrm{~K}$. This TDC density range corresponds to intake pressures from 0.67 to 2 atmospheres absolute for the production version of this engine, which has a compression ratio of 16:1.

For all conditions, the liquid phase-fuel penetrated almost linearly with time for the first few degrees until it reached a characteristic maximum penetration length that varied with operating condition. After reaching its maximum value, the liquid-length remained fairly constant, even though fuel continued to be injected. Since the maximum fuel penetration length was reached prior to significant heat release, the liquid-fuel penetration length was limited strictly by the entrainment of the hot in-cylinder air into the liquid spray.

The parametric TDC temperature variation produced the following results:

1. The liquid-fuel penetration rates are nearly identical up to the point of maximum penetration.

2. The maximum liquid-penetration length varied from 18 to $30 \mathrm{~mm}$ for TDC temperatures from $1100 \mathrm{~K}$ to $800 \mathrm{~K}$, respectively.

3. As TDC temperature is increased, the ignition delay and the premixed burn fraction progressively decrease, with ignition delays varying from $8.5^{\circ} \mathrm{CA}$ at $800 \mathrm{~K}$ to $3.0^{\circ} \mathrm{CA}$ at $1100 \mathrm{~K}$.

The parametric TDC density variation produced the following results:

1. The initial liquid-fuel penetration rates are nearly the same, but the penetration rates decrease more rapidly at higher densities.

2. The maximum liquid-penetration length varied from 13 to $30 \mathrm{~mm}$ for TDC densities from 32.2 to $11.1 \mathrm{~kg} / \mathrm{m}^{3}$ (simulated intake pressures of 2 to 0.67 atmospheres absolute), respectively.

3. As TDC density is increased, the ignition delay and the premixed burn fraction progressively decrease, with ignition delays varying from $7.5^{\circ} \mathrm{CA}$ at $11.1 \mathrm{~kg} / \mathrm{m}^{3}$ to $1.5^{\circ}$ $\mathrm{CA}$ at $33.2 \mathrm{~kg} / \mathrm{m}^{3}$.

The range of TDC temperatures and densities examined covers a major portion of the typical Diesel operating regime. The measurements showed that both TDC temperature and density can significantly affect the liquid-phase fuel penetration. The comparison between the images and the heat release data shows that there exists a strong correlation between maximum liquid-fuel penetration length and both ignition delay and premixed burn fraction. Over a typical warm-engine operating range, the TDC density has a greater effect on both the maximum liquid-phase penetration and on the ignition delay than does the TDC temperature. The data show that, in this type of engine, liquid-fuel wall impingement will not occur even under moderate cold start conditions.

\section{ACKNOWLEDGMENTS}

The authors would like to thank Eldon Porter for his help in building the experimental apparatus and for help with the data acquisition. The authors would also like to express their gratitude to Patrick Flynn of Cummins Engine Co. for his support of this project.

This study was performed at the Combustion Research Facility, Sandia National Laboratories, Livermore, CA. The authors thank the Cummins Engine Company and the U.S. Department of Energy, Defense Programs Technology Transfer Initiative for supporting this work.

\section{REFERENCES}

1. Lyn, W. T., and Valdmanis, E., "The Application of High Speed Schlieren Photography to Diesel Combustion Research", Journal of Photographic Science, Vol. 10, 1962.

2. Huber, F. W., Stock, D., and Pischinger, F., "Investigation of Mixture Formation and Combustion in a Diesel Engine with the Aid of Schlieren Method," 9th International Congress on Combustion Engines (CIMAC), Stockholm, Sweden, 1971.

3. Rife, R. and Heywood, J. B., "Photographic and Performance Studies of Diesel Combustion With a Rapid Compression Machine, SAE Transactions, Vol. 83, Sec. 4, pp. 2942-2953, paper no. 740948, 1974.

4. Kobayashi, H., Kamimoto, T., and Matsuoka, S., "A Photographic and Thermodynamic Study of Diesel Combustion in a Rapid Compression Machine, SAE Transactions, Vol. 90, Sec. 2, pp. 1149-1160, paper no. 810259, 1981.

5. Browne, K. R., Partridge, I. M., and Greeves, G., "Fuel Property Effects on Fuel/Air Mixing in an Experimental Diesel Engine," SAE paper 860223, 1986.

6. Arold, M. L., Espey, C., Litzinger, T. A., Santavicca, D. A., Santoro, R. J., "A Study of Non-Swirling and Swirling Flow Fields and Their Effects on Spray Flow Fields and Combustion in an Optically-Accessible, DI Diesel Engine", SAE Transactions, Vol. 99, Sec. 3, pp. 916-928, paper no. 900396, 1990.

7. Espey, C., Pinson, J. A., Litzinger, T. A., "Swirl Effects on Mixing and Flame Evolution in a Research DI Diesel Engine", SAE Transactions, Vol. 99, Sec. 3, pp. 20792088, paper no. 902076, 1990.

8. Edwards, C. F., Siebers, D. L., and Hoskin, D. H, "A Study of the Autoignition Process of a Diesel Spray via High Speed Visualization," SAE Transactions, Vol. 101, Sec. 3, pp. 187-204, paper no. 920108, 1992.

9. Kamimoto, T., Kobayashi, H., and Matusoka, S.: "A Big Size Rapid Compression Machine for Fundamental Studies of Diesel Combustion", SAE Transactions, Vol. 90, Sec. 3, pp. 3135-3143, paper no. 811004, 1981.

10. Kamimoto, T., Yokota, H., and Kobayashi, H., "Effect of High Pressure Injection on Soot Formation Processes in a Rapid Compression Machine to Simulate Diesel Flames," SAE Transactions, Vol. 96, Sec. 4, pp. 4.783-4.791, paper no. 871610, 1987. 
11. Eckbreth, A., Laser Diagnostics for Combustion Temperature and Species, p. 9, Abacus Press, Cambridge, Mass., 1988.

12. Melton, L. A., Verdieck, J. F., "Vapor/Liquid Visualization in Fuel Sprays", Twentieth Symposium (International) on Combustion, The Combustion Institute, pp. 1283-1290, 1984.

13. Melton, L. A., Verdieck, J. F., "Vapor/Liquid Visualization for Fuel Sprays", Combustion Science and Technology, Vol. 42, pp. 217-222, 1985.

14. Bardsley, M. E. A., Felton, P. G., and Bracco, F. V., "2$D$ Visualization of Liquid and Vapor Fuel in an I.C. Engine," SAE Transactions, Vol. 97, Sec. 3, pp. 3.2813.291, paper no. 880521, 1988.

15. Hodges, J. T., Baritaud, T. A., and Heinze, T. A.: "Planar Liquid and Gas Fuel and Droplet Size Visualization in a DI Diesel Engine," SAE Transactions, Vol. 100, Sec. 3, pp. 1284-1302, paper no. 910726, 1991.

16. Senda, J., Fukami, Y., Tanabe Y. and Fujimoto, H., "Visualization of Eyaporative Diesel Spray Impinging Upon Wall Surface by Exciplex Fluorescence Method", SAE Transactions, Vol. 101, Sec. 3, pp. 1054-1063, paper no. 920578, 1992.

17. Melton, L. A., "Quantitative Use of Exciplex-based Vapor/Liquid Visualization Systems (A Users Manual)," Final Report U.S. Army Research Office Contract DAAL03-86-K-0082, (1988). (NTIS Order \# ADA191649.)

18. Felton, P. G., Bracco, F. V., Bradsley, M. E. A., "On the Quantitative Application of Exciplex Fluorescence to Engine Sprays", SAE paper no. 930870, 1993.

19. Kosaka, H., Won, Y. H. and Kamimoto, T., "A Study of the Structure of Diesel Sprays Using 2-D Imaging Techniques", SAE Transactions, Vol. 101, Sec. 3, pp. 175186, paper no. 920107, 1992.

20. Yeh, C.-N., Kamimoto, T., Kosaka, H., and Kobori, S., "Quantitative Measurement of 2-D Fuel Vapor Concentration in a Transient Spray via Laser-Induced Fluorescence Technique," SAE paper no. 941953, 1994.

21. Baritaud, T.A., Heinze, T.A., and Le Cox, J.F., "Spray and Self-Ignition Visualization in a DI Diesel Engine," SAE paper no. 940681, 1994.

22. Kosaka, H. and Kamimoto, T., "Quantitative Measurement of Fuel Vapor Concentration in an Unsteady Evaporating Spray via a 2-D Mie-Scattering Imaging Technique", SAE paper no. 932653, 1993.

23. Dec, J. E. and Espey, C., "Soot and Fuel Distributions in a D.I. Diesel Engine via 2-D Imaging," SAE Transactions, Vol. 101, Sec. 4, pp. 1642-1651, paper no. 922307 , 1992.

24. Espey, C., Dec, J. E., Litzinger, T. A. and Santavicca, D. A., "Quantitative 2-D Fuel Vapor Concentration Imaging in a Firing D.I. Diesel Engine Using Planar Laser-Induced Rayleigh Scattering," in press SAE Transactions, SAE paper no. 940682, 1994.
25. Espey, C., Dec, J. E., Litzinger, T. A. and Santavicca, D. A., "Quantitative Planar Rayleigh Scattering for Fuel Vapor Concentration Imaging in a Diesel Fuel Jet," submitted to Combustion and Flame, 1994.

26. zur Loye, A. O., Siebers, D. L., McKinley, T. L., Ng, H. K., and Primus, R. J., "Cycle-Resolved LDV Measurements in a Motored Diesel Engine and Comparison with k- $\varepsilon$ Model Predictions," SAE Transactions, Vol. 98, Sec. 3, pp. 1142-1158, paper no. 890618, 1989.

27. Bowditch, F. W., "A New Tool for Combustion Research - A Quartz Piston Engine," SAE Transactions, Vol. 69, pp. 17-23, 1961.

28. Espey, C. and Dec, J. E., "Diesel Engine Combustion Studies in a Newly Designed Optical-Access Engine Using High-Speed Visualization and 2-D Laser Imaging," SAE Transactions, Vol. 102, J. Fuels and Lubricants, Sec. 4, pp. 703-723, paper no. 930971, 1993.

29. Dec, J. E. and Espey, C., "Ignition and Early Soot Formation in a D.I. Diesel Engine Using Multiple 2-D Imaging Diagnostics," SAE paper 9504561, 1995.

30. Dec, J. E. and Espey, C., "Soot and Liquid-Phase Fuel Distributions in a Newly Designed Optically Accessible D.I. Diesel Engine," Presented at the 1993 Diesel Emission Reduction Workshop, LaJolla, CA, July 1993, Sandia Laboratories Report No. SAND93-8690C.

31. Heywood, J. B., Internal Combustion Engine Fundamentals, pp. 509-511, McGraw-Hill, 1988.

32. Born, M., and Wolf, E., Principles of Optics, p. 90, Pergamon Press, Oxford, 1975.

33. Jenkins, F. A., White, H. E., Fundamentals of Optics, McGraw-Hill, Inc., New York, 1976, 4th edition.

34. Kerker, M., The Scattering of Light and Other Electromagnetic Radiation, Academic Press, San Diego, California, 1969, p. 37.

35. Van de Hulst, H. C., Light Scattering by Small Particles, John Wiley \& Sons, Inc., New York, 1957.

36. Bohren, C. F., Huffman, D. R., Absorption and Scattering of Light by Small Particles, John Wiley \& Sons, Inc., New York, 1983.

37. Espey, C., "Fuel-Air Mixing and Ignition in a DI Diesel Engine", Ph.D. Thesis, The Pennsylvania State University, 1995.

38. Arai, M., Tabata, M., Hiroyasu, H. and Shimizu, M., "Disintegrating Process and Spray Characterization of Fuel Jet Injected by a Diesel Nozzle," SAE Transactions, Vol. 93, Sec. 2, pp. 2.358-2.371, paper no. 840275, 1984.

39. Ciezki, H.K., and Adomeit, G., Combustion and Flame, Vol. 93, pp. 421-433, 1993.

40. Gaffuri, P., Curran, H.J., Pitz, W.J., and Westbrook, C.K., "Combustion of n-Heptane in a Shock Tube and in a Stirred Reactor: A Detailed Kinetic Modeling Study," Proceeding of the Joint Technical Meeting of the Central and Western States Sections of the International Combustion Institute, San Antonio, TX, April 23-26, 1995. 

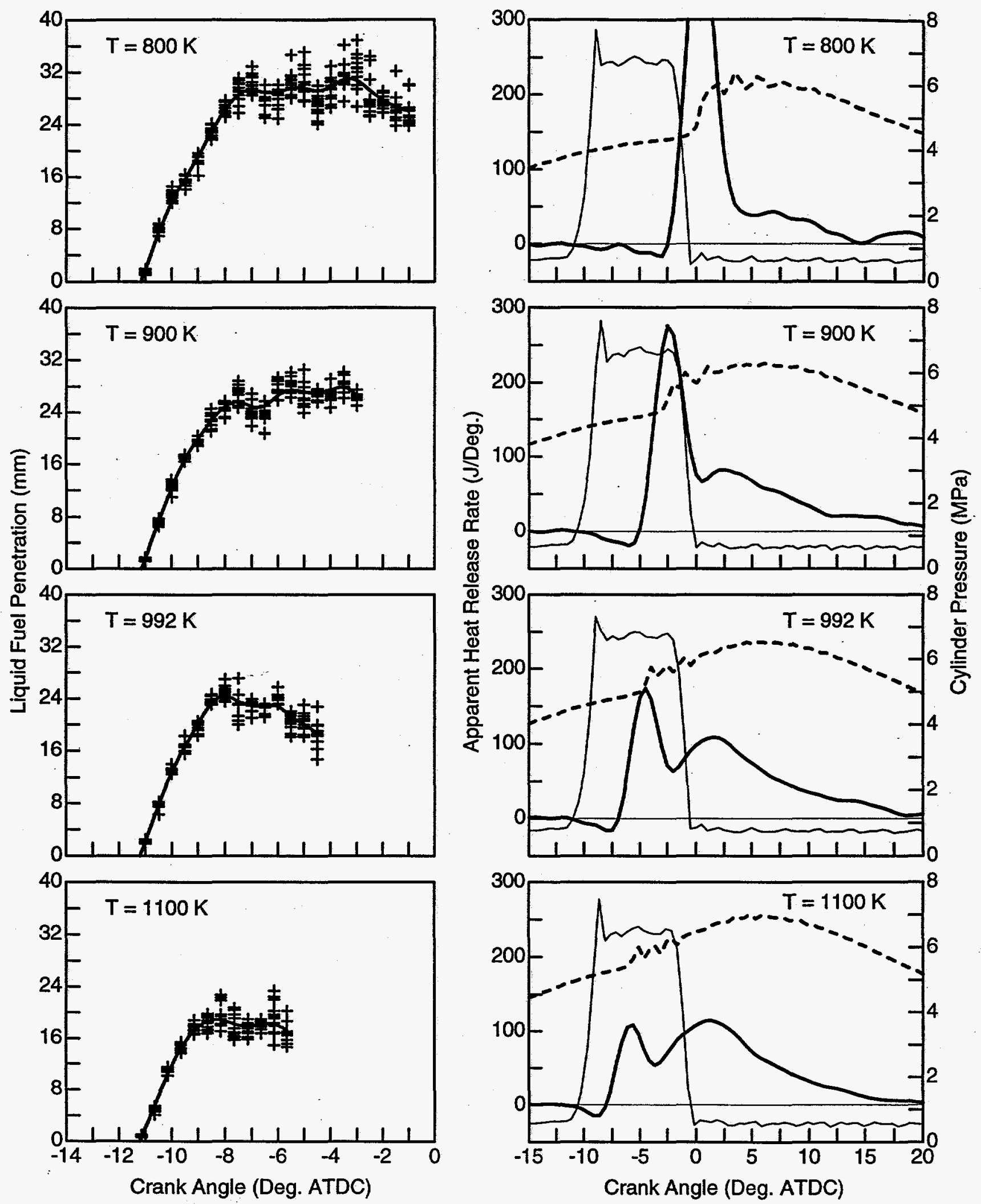

+ Liquid Penetration $\quad$ - Heat Release Rate $\quad$ - Cylinder Pressure - Needle Lift

Figure A1. Liquid-phase fuel penetration showing the data points for all 12 cycles and the cubic-spline curve fits (left), and apparent heat release rate, cylinder pressure and needle lift (right) for the four TDC temperatures examined at a simulated intake pressure of 1.0 atmosphere (TDC density of $16.6 \mathrm{~kg} / \mathrm{m}^{3}$ ). The data in the right hand plots are ensemble-averaged over $20 \mathrm{cycles}$. 

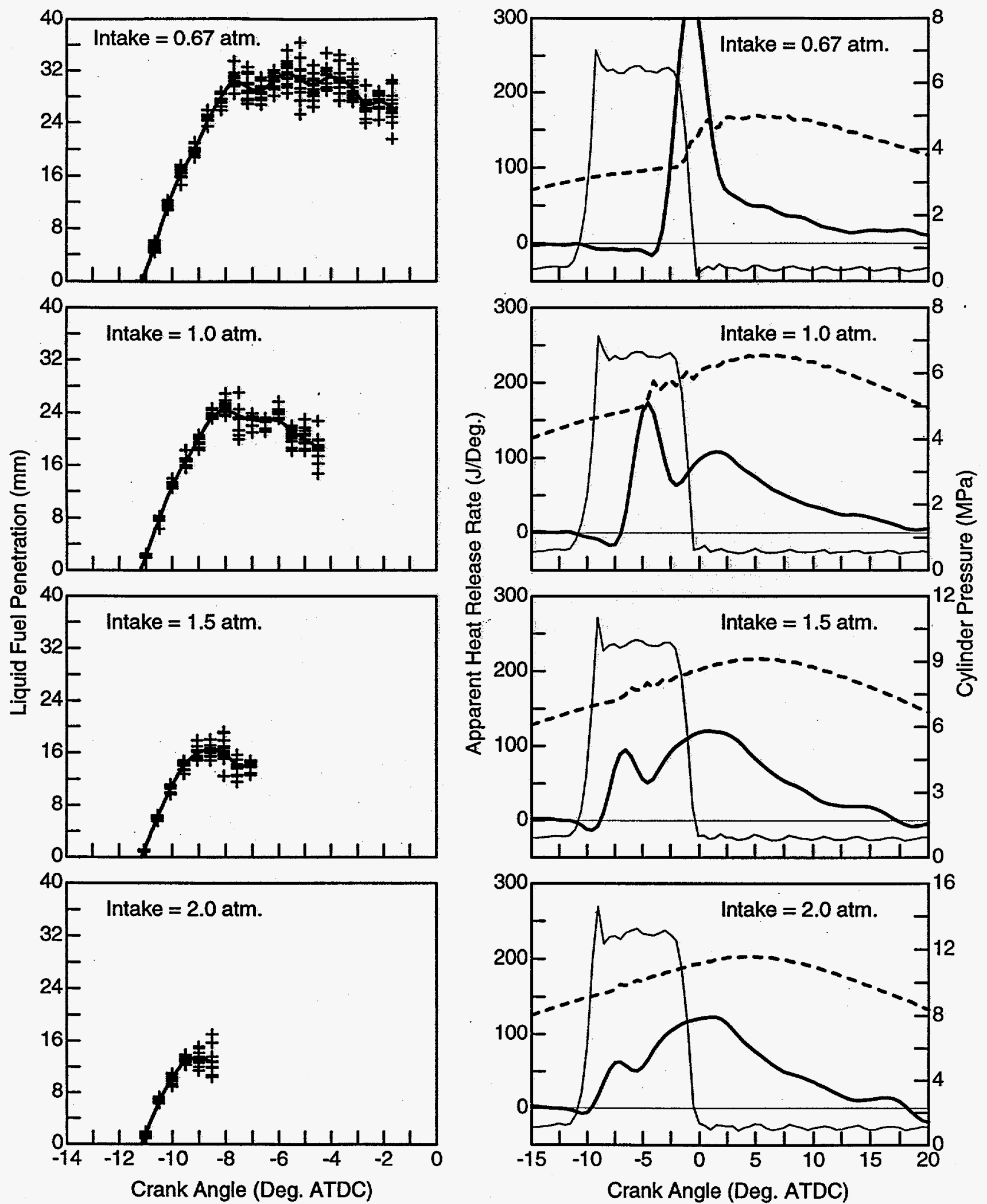

\section{++ Liquid Penetration - Heat Release Rate - Cylinder Pressure - Needle Lift}

Figure A2. Liquid-phase fuel penetration showing the data points for all 12 cycles and the cubic-spline curve fits (left), and apparent heat release rate, cylinder pressure and needle lift (right) for the four simulated intake pressures (TDC densities) examined at a constant TDC temperature of $992 \mathrm{~K}$. The data in the right hand plots are ensemble-averaged over 20 cycles. 


\section{DISCLAIMER}

This report was prepared as an account of work sponsored by an agency of the United States Government. Neither the United States Government nor any agency thereof, nor any of their employees, makes any warranty, express or implied, or assumes any legal liability or responsibility for the accuracy, completeness, or usefulness of any information, apparatus, product, or process disclosed, or represents that its use would not infringe privately owned rights. Reference herein to any speciric commercial produch, process, or service by trade name, trademark, manufacturer, or otherwise does not necessarily constitute or imply its endorsement, recommendation, or favoring by the United States Governmeat or any agency thereof. The views and opinions of authors expressed herein do not necessarily state or reflect those of the United States Government or any agency thereof. 